\title{
Association of spectroscopically determined leaf nutrition related traits and breeding selection in Sassafras tzumu
}

\section{Jun Liu}

Research Institute of Subtropical Forestry Chinese Academy of Forestry https://orcid.org/0000-00030245-1705

\section{Yang Sun}

Research Institute of Subtropical Forestry Chinese Academy of Forestry

Wenjian Liu

Research Institute of Subtropical Forestry Chinese Academy of Forestry

\section{Zifeng Tan}

Research Institute of subTropical Forestry Chinese Academy of Forestry

\section{Jingmin Jiang}

Research Institute of Subtropical Forestry Chinese Academy of Forestry

\section{Yanjie Li ( $\nabla$ aj7105@gmail.com )}

https://orcid.org/0000-0001-7750-757X

\section{Research}

Keywords: spectroscopy, Anthocyanins (ANTH), flavonoids (FLAV), Nitrogen balance index (NBI), breeding selection

Posted Date: January 25th, 2021

DOI: https://doi.org/10.21203/rs.3.rs-48543/v2

License: (a) (1) This work is licensed under a Creative Commons Attribution 4.0 International License. Read Full License

Version of Record: A version of this preprint was published at Plant Methods on March 31st, 2021. See the published version at https://doi.org/10.1186/s13007-021-00734-5. 


\title{
Association of spectroscopically determined leaf nutrition
}

\section{related traits and breeding selection in Sassafras tzumu}

\author{
Jun Liu ${ }^{1 \#}$, Yang Sun ${ }^{1, \#}$, Wenjian Liu ${ }^{1}$, Zifeng Tan ${ }^{1}$, Jingmin Jiang ${ }^{1}$ and Yanjie $\mathrm{Li}^{1 *}$
}

1, Research Institute of Subtropical Forestry, Chinese Academy of Forestry, Fuyang 311400, Zhejiang, China

2, College of Forestry, Nanjing Forestry University, Nanjing, P. R. China

\# These authors contributed equally to this work

*Correspondence: Yanjie Li, aj7105@gmail.com

\begin{abstract}
:
Background: Plant traits related to nutrition have an influential role on tree growth, tree production and nutrient cycling. Therefore, the breeding program should consider the genetics of the traits. However, the measurement methods could seriously affect the progress of breeding selection program. In this study, we tested the ability of spectroscopy to quantify the specific leaf nutrition traits including Anthocyanins (ANTH), flavonoids (FLAV) and Nitrogen balance index (NBI), and estimated the genetic variation of these leaf traits based on the spectroscopic predicted data. Live fresh leaves of Sassafras tzumu were selected for spectral collection, after which concentrations of ANTH, FLAV and NBI were analyzed by standard analytical methods. Partial least squares regression (PLSR), five spectra pre-processing methods, and four variable selection algorisms were conducted for the optimal prediction model selection. Each trait model was simulated 200 times for error estimation.
\end{abstract}

Results: The Standard Normal Variate (SNV) to the ANTH model and $1^{\text {st }}$ derivatives to the FLAV and NBI models, combined with significant Multivariate Correlation (sMC) algorithm variable selection are finally regarded as the best performance model. The ANTH model produced the highest accuracy of prediction with a mean $\mathrm{R}^{2}$ of 0.72 and mean RMSE of $0.10 \%$, 
followed by FLAV and NBI model (mean $\mathrm{R}^{2}=0.58$, mean $\mathrm{RMSE}=0.11 \%$ and mean $\mathrm{R}^{2}=0.44$, mean RMSE $=0.04 \%$ ). High heritability was found of ANTH FLAV and NBI with $h^{2}$ of 0.78 , 0.58 and 0.61 respectively. It shows that it is benefitting and possible of breeding selection for the improvement of leaf nutrition traits.

Conclusions: Spectroscopy can successfully characterize the leaf nutrition traits in living tree leaves and the ability to simultaneous multiple plant traits provides a promising and highthroughput tool for the quick analysis of large size samples and serves for genetic breeding program.

Keyword: spectroscopy; Anthocyanins (ANTH); flavonoids (FLAV); Nitrogen balance index (NBI), breeding selection

\section{Background}

Nitrogen $(\mathrm{N})$ is one of the most essential nutrients in plant growth, which is needed to improve grain yield and quality (Cánovas et al., 2018). Excessive $\mathrm{N}$ fertilizer application creates severe environment problems, while inadequate $\mathrm{N}$ availability limits productivity. Hence, precise $\mathrm{N}$ application in the plant is an important goal (Srinivasan, 2006). The N status of the plant should be precisely measured during growth to guide precise fertilization (Payne et al., 2017). $\mathrm{N}$ is the most common limiting factor for the individual, natural and artificial ecosystems growth of the plant. Plants require $\mathrm{N}$ to maintain for growth mainly through external and internal sources, including soil organic matter, fertilizers, atmospheric deposition and stored $\mathrm{N}$ by plant themselves (Millard, 1996). Plants, such as boreal species, store $\mathrm{N}$ seasonally through the process of internal cycling and it is a major source of $\mathrm{N}$ supplement for tree growth especially when the external availability of $\mathrm{N}$ is limited (Nambiar and Fife, 1991; Millard and Proe, 1993). Trees store $\mathrm{N}$ as proteins mainly in their perennial wood and bark tissues in summer and winter. In addition, other parts of foliage trees, like roots and leaves, also store $\mathrm{N}$ which provides nutrition for young roots and needles development. Tree $\mathrm{N}$ remobilisation often occurs during 
the growth season. The stored $\mathrm{N}$ mainly determines the amount of $\mathrm{N}$ remobilised and plays an important role for the tree seasonal growth (Cooke and Weih, 2005; Villar-Salvador et al., 2015; Babst and Coleman, 2018). The dynamics and mobilization of $\mathrm{N}$ stored in trees have been widely studied (Cyr et al., 1990; Malagoli et al., 2005). The variation of plant species, genotype, soil and environment leads to the diversity of leaf nitrogen content (Sinclair and Horie, 1989; Famula et al., 2019). It is reported that the chlorophyll content has a strong positive correlation with $\mathrm{N}$ content which is an estimative index for $\mathrm{N}$ status in leaf (Wood et al., 1993). Chlorophyll content is measured as a proxy for leaf N status (Evans 1983) and non-destructive, spectroscopic, chlorophyll meters have been available for decades (Evans, 1983; Monje and Bugbee, 1992; Markwell et al., 1995; Huang and Peng, 2004; Moreau et al., 2004; Hardin et $a l ., 2012$ ). In addition to chlorophyll the content of flavonoids (FLAV), one of the main polyphenolic components of the plant, is also correlated with the $\mathrm{N}$ status of the leaf (Tremblay et al., 2012). Evidence shows that the rise of $\mathrm{N}$ fertilization will lead to flavonoid content decreasing and chlorophyll content increasing (Padilla et al., 2014). Another N status index, N balance index (NBI), which is the ratio of chlorophyll to flavonoid, is verified that it has a better and more reliable correlation with leaf $\mathrm{N}$ concentration than chlorophyll content alone (Tremblay et al., 2012).

Anthocyanins (ANTH) are a group of water soluble flavonoid pigments that occur in all plant tissues. Anthocyanins are mostly related to a wide range of plant colour but often appear as red (Croft and Chen, 2017). In addition, unfavourable conditions will transiently have an impact on anthocyanins accumulation in both juvenile and senescent observable plant leaves (Garriga et al., 2014; Naing et al., 2017; Trojak and Skowron, 2017). Thus, Anthocyanins are taken as an indicator of plant leaf senescence and stresses (Paul et al., 2017; Liu et al., 2019).

However, research on plant growth and the variation of $\mathrm{N}$ storage and remobilization have typically required labour intensive methods to measure the $\mathrm{N}$ concentration and index 
properties (NBI, chlorophyll content, ANTH, and FLAV), such as atomic absorption spectrometry (Borges and Holcombe, 2017; Hu et al., 2019), chromatography (Rivero-Villar et al., 2018) and so on. These analytical methods will limit the breeding selection of tree growth with a large number of samples.

Alternatively, Near-infrared spectroscopy (NIRS) is a rapid, high-throughput technique that has been used for chemical components analysis in many fields. NIRS is a promising and reliable method that can be used for the assessment of a large number of samples (Forina et al., 2015; Ramirez et al., 2015; Guillemain et al., 2017; Malegori et al., 2017; Li et al., 2018a). NIRS relies on the absorption of light at specific wavelengths because of the vibration, stretching and bending of molecular bonds, including $\mathrm{C}-\mathrm{H}, \mathrm{N}-\mathrm{H}$ and $\mathrm{O}-\mathrm{H}$ bonds (Bokobza, 2002), will interact with the specific wavelengths in the NIR spectroscopy.

Multivariate methods such as partial least squares regression (PLSR) (Wold et al., 2001) will be used to create a prediction model between NIR spectra and the independent chemical measurements. PLSR holds the advantages of producing reliable coefficients, reducing the bias and estimated error, and consuming fewer PLSR components, all of which make it one of the most popular methods for chemometric analyses (Bolster et al., 1996; Asner et al., 2011). The model will then be applied to unknown samples by their spectra data for independent chemical prediction. Our recent research shows that leaf chlorophyll content and colour parameters are predictable on fresh leaf samples with field near infrared spectrophotometry (Li et al., 2019). The total FLAV and ANTH concentration also have been predicted by a general calibration model in Ginkgo biloba leaf and four Indonesian herbal plant species, including Syzigium oleana, Piper betle, Jasminum and Graptophyllum pictum with NIR reflectance spectroscopy. NIR is a promising tool for tree breeding selection programs due to its robustness and capacity to screen large numbers of samples (Gebreselassie et al., 2017; Li et al., 2019). 
The robustness and reliability of model accuracy are largely determined by the spectra quality and feature selection. The combinations vibrations information and noise of the raw NIR spectra (Yang et al., 2018) will result in overlapping and difficulty to directly distinguish the target plant properties (Inagaki et al., 2018). Spectra pre-processing methods, can efficiently reduce the overlapping and noise influence, such as stander normal variation (SNV) (Barnes et al., 1989), $1^{\text {st }}$ and $2^{\text {nd }}$ derivatives and so on (Jin et al., 2017; Park et al., 2018). To yield a robust and reliable model and avoid the influence of irrelevant variables and noise, it is essential to carry out variable selection methods to pick the most relevant variables responding to the target properties instead of the full length of spectra (Fernández et al., 2019; Liang et al., 2020).

The joint analyses of chemometric statistics and variable selection algorithms has recently been used to eliminate the irrelevant variables and improve the model accuracy (Caliari et al., 2017; Mancini et al., 2018). The most common methods of variable selection are Genetic algorithm (Ga) (Zhao and Cao, 2016), Regularized elimination procedure (Rep) algorithm (Mehmood et al., 2012), Iterative predictor weighting (Ipw) (Forina et al., 1999) and significant Multivariate Correlation (sMC) algorithm (Tran et al., 2014). However, the comparison of variable selection algorithms along with PLSR for prediction of multiple leaf nutrition traits is less studied.

Sassafras tzumu is a deciduous tree species that has colourful leaves in autumn. Zhejiang province in China is vigorously promoting the cultivation of colourful species making S. tzumu a famous tree species. It has been widely planted in Zhejiang province to develop the urban and mountain landscape (Jiang aiping et al., 2016).

Our latest study addresses whether leaf colour and chlorophyll and variation of leaf nutrition traits (NBI, ANTH and FLAV) in S. tzumu are heritable (Li et al., 2019).

Therefore, the aims of this research are to 1) test the capacity of reflectance spectroscopy to characterize the NBI, ANTH and FLAV with PLSR model; 2) find out the most optimal preprocessing method for these three leaf traits. 3) identify the most important wavelength that 
related to NBI, ANTH and FLAV by four variable selection methods, including significant multivariate correlation (sMC), regularized variable elimination procedure (Rep), iterative predictor weighting (Ipw), and Genetic algorithm (Ga) variable selection; 4) estimate genetic parameters and correlations of NBI, ANTH and FLAV in S. tzumu.

\section{Methods and materials}

\section{Materials}

50 half-sib families of $S$. tzumu were selected for our study from 6 different regions. Trees were planted in 2016 using a randomised complete block by a $2 \mathrm{~m} \times 3 \mathrm{~m}$ spacing in Changle Forest Farm Nursery $\left(30^{\circ} 27^{\prime} \mathrm{N}, 119^{\circ} 48^{\prime} \mathrm{E}\right)$, Hangzhou, Zhejiang, China. Each family replicated 30 times with 5 replications and 6 individual trees per replication. In total, 1500 trees were planted.

\section{NIR spectra collection}

Samples spectra data was collected through 5-6 leaves of each tree from the top to bottom with similar color on the same side in October 2018. The NIR spectra data was taken from the upside surface of the leaves for three times with a handheld fibre optic contact probe from a field-based spectrometer (LF-2500, Spectral evolution, USA). Each spectrum took on average 32 scans with a range of 1100 to $2500 \mathrm{~nm}$ by a $6 \mathrm{~nm}$ resolution. All spectra were obtained from the leaves of 1500 trees, 500 trees leaves from these 1500 trees were sampled and placed in a marked paper bag and transferred to the refrigerator immediately for chemical measurement.

\section{Leaf FLAV measurement}

Each leaf was ground into powder and being mixed with methanol for $24 \mathrm{hrs} .0 .5 \mathrm{ml}(1 \mathrm{mg} / \mathrm{mL})$ extract of each sample was taken to mixed with methanol $(1.5 \mathrm{ml}), 10 \%$ aluminium chloride $(0.1 \mathrm{ml}), 1 \mathrm{M}$ potassium acetate $(0.1 \mathrm{ml})$ and distilled water $(2.8 \mathrm{ml})$. The mixture was being placed under room temperature for 30 mins and then measured at $415 \mathrm{~nm}$ for the absorbance 
by UV-Visible spectrophotometer (UV-1280, Shimadzu, Japan). The flavonoid content of the sample was accessed by the value of absorbance density (Eom et al., 2007).

\section{Pigment extraction and NBI estimation}

A weighed circular piece cutting from each leaf was place into a mortar by a pestle ground with $100 \%$ methanol until the colour changed into white. The extract was being centrifuged for 6 mins by $14,000 \mathrm{rpm}$ at $4{ }^{\circ} \mathrm{C}$ and subsequently assayed by a UV-Visible spectrophotometer (UV-1280, Shimadzu, Japan). It conducted the equation and specific absorption in the wavelength which was reported by Wellburn (1994). The solution was mixed with $3 \mathrm{ml}$ acidified methanol $(1 \% \mathrm{HCl})$ at $4{ }^{\circ} \mathrm{C}$ with moderate shaking for $12 \mathrm{hrs}$ and then being centrifuged for $10 \mathrm{mins}$ at $14,000 \mathrm{rpm}$. The extraction was then placed into the spectrophotometer, and it took the absorption at 530 and $657 \mathrm{~nm}$ wavelengths to determine the ANTH concentration (Strack and Wray, 1989). The NBI index was figured as the ratio of chlorophyll to flavonoid content.

\section{Model calibration and validation}

In total, 500 trees were The original five different types of pre-processing spectra $\left(\mathrm{SNV}, 1^{\text {st }}\right.$, $2^{\text {nd }}$ derivatives, $\mathrm{SNV}+1^{\text {st }}$ derivatives, $\mathrm{SNV}+2^{\text {nd }}$ derivatives) combined with PLSR (Wold $e t$ $a l ., 2001)$ algorithm were compared in our study. The Savitzky-Golay smoothing (Press and Teukolsky, 1990) with a window size of 15 data points was applied in both $1^{\text {st }}$ and $2^{\text {nd }}$ derivatives spectra. PLSR models were generated with leave-one-out cross-validation for the prediction of ANTH, NBI, and FLAV content. Data were randomly split 200 times into calibration (80\%) for model building and validation (20\%) for model test respectively. Therefore, the PLSR model has been conducted 200 times for the evaluation of model performance. Each model combined with four variable selections (sMC, Ipw, Rep and Ga) was conducted to find out the most important spectral variables. The coefficient of determination 
$\left(\mathrm{R}^{2}\right)$ and root-mean-square error (RMSE) in each model derived from both calibration (Cal) and validation (Val) were applied for the evaluation model performance.

\section{Statistical analysis}

The estimation of genetic parameters were measured by A multivariate restricted maximum likelihood (REML) linear mixed model, details can be found in (Li et al., 2018a). The narrow sense heritability $\left(h^{2}\right)$ of trait $i$ and genetic correlations $\left(r_{g_{i j}}\right)$ and phenotypic correlation $\left(r_{p_{i j}}\right)$ between trait $i$ and trait $j$ were calculated as:

$h_{i}^{2}=\frac{2.5 \sigma_{f_{i}}^{2}}{\sigma_{f_{i}}^{2}+\sigma_{e_{i}}^{2}}$

$r_{g_{i j}}=\frac{\sigma_{f i f j}}{\sqrt{\sigma_{f_{i}}^{2}+\sigma_{f_{j}}^{2}}}$

$r_{p_{i j}}=\frac{\sigma_{f i f j}+\sigma_{e i e j}}{\sqrt{\left(\sigma_{f_{i}}^{2}+\sigma_{e_{i}}^{2}\right)\left(\sigma_{f_{j}}^{2}+\sigma_{e_{j}}^{2}\right)}}$

where $\sigma_{f_{i}}^{2}$ is the estimated family variance for trait $i$, and $\sigma_{f_{j}}^{2}$ is the estimated family variance for trait $j, \sigma_{e_{i}}^{2}$ and $\sigma_{e_{j}}^{2}$ are the residual variances for trait $i$ and $j$, and $\sigma_{f i f j}$ and $\sigma_{e i e j}$ are the family and residual covariances between traits $i$ and trait $j$. The random effects of each family were set as breeding values. The realized genetic gain $\left(\Delta G_{R}\right)$ was calculated by the difference between the mean breeding values of selected top ratio leaf traits and the total mean of the leaf traits.

R software (version 3.1.2) (R Core Team, 2017) was taken for all of the data analysis. The pls package (Mevik et al., 2015) in R was carried out for PLSR model building, the plsVarSel (Mehmood et al., 2012) for variables selection, the prospectr package (Stevens and RamirezLopez, 2014) for NIR spectra manipulation, the lme4 package (Bates et al., 2015) for estimation of genetic parameters, and the ggplot2 package (Wickham, 2016) for visualization plot. 


\section{Results}

\section{Model performance}

Three leaf traits ANTH, FLAV and NBI constructed the NIR spectral PLSR model. The results are shown in Figure 1. ANTH model has the highest accuracy, followed by FLAV and NBI model. The average of $\mathrm{R}^{2}$ and RMSE for these three models in calibration (Cal) sets is 0.54 (range: $0.43-0.63$ ), 0.47 (range: $0.35-0.58$ ) and 0.36 (range: $0.26-0.45$ ), in validation (Val) sets is 0.54 (range: $0.28-0.75$ ), 0.47 (range: $0.28-0.69$ ) and 0.38 (range: $0.25-0.64$ ) respectively. As for all spectral pre-processing models, $\mathrm{SNV}+2^{\text {nd }}$ derivative prediction model is found to be the highest well-performing for predicting ANTH concentration than the other pre-processing methods, with a mean $\mathrm{R}^{2} \mathrm{Cal}$ and $\mathrm{RMSE}_{\mathrm{Cal}}$ of 0.59 (range: $0.55-0.63$ ), $0.11 \%$ (range: 0.11 $0.12 \%$ ), a mean $\mathrm{R}^{2} \mathrm{Val}$ and $\mathrm{RMSEval}$ of 0.57 (range: $0.38-0.72$ ), $0.11 \%$ (range: $0.09-0.13 \%$ ), followed by $2^{\text {nd }}, \mathrm{SNV}+1^{\text {st }}, 1^{\text {st }}$, original with the mean of $\mathrm{R}^{2}$ in Cal is 0.56 (range: $0.42-0.75$ ), 0.56 (range: $0.51-0.60$ ), 0.53 (range: $0.48-0.59$ ), 0.52 (range: $0.47-0.56$ ), and RMSE $0.11 \%$ (range: $0.11-0.12 \%)$, ), $0.11 \%$ (range: $0.11-0.12 \%$ ), $0.11 \%$ (range: $0.11-0.12 \%$ ), $0.12 \%$ (range: $0.11-0.12$ ), and in $\mathrm{Val}$ is 0.57 (range: $0.42-0.75$ ), 0.54 (range:0.30-0.70), 0.53 (range: 0.36 0.67), 0.52 (range: $0.32-0.72$ ), and RMSE $0.11 \%$ (range: $0.09-0.13 \%$ ), $0.12 \%$ (range: 0.10 $0.14 \%$ ), $0.12 \%$ (range: $0.10-0.14 \%$ ), $0.11 \%$ (range: $0.09-0.14 \%$ ) respectively. SNV shows the worst effect with the mean of $\mathrm{R}^{2}$ and RMSE for Cal and Val 0.49 (range: 0.44-0.54), 0.49 (range: $0.28-0.63$ ), and $0.13 \%$ (range: $0.13-0.14 \%$ ), $0.13 \%$ (range: $0.12-0.16 \%$ ) respectively. However, $1^{\text {st }}$ yields the best PLSR model in the prediction of FLAV and NBI than the other pre-processing model, with high mean $\mathrm{R}^{2} \mathrm{Cal} \mathrm{R}^{2}$ Val of 0.51 (range: 0.46-0.58), 0.52 (range: 0.290.68), and low mean of RMSEcal, RMSEval of 0.12\% (range: 0.11-0.13\%), 0.12 (range: 0.10$0.12 \%$ ) in FLAV model and high mean $\mathrm{R}^{2}$ Cal, $\mathrm{R}^{2}$ Val of 0.39 (range: $0.33-0.45$ ), 0.41 (range: 0.26-0.60), and low mean of RMSE ${ }_{\text {Cal }}, \mathrm{RMSEV}_{\mathrm{V}}$ of $0.05 \%$ (range: 0.05-0.05\%), 0.05 (range: 0.04-0.06\%) in NBI model respectively. The effect of SNV shows a poor prediction in the 
FLAV and NBI as well. The mean of $\mathrm{R}^{2}$ Val is 0.40 (range: $0.26-0.64$ ) and 0.47 (range: 0.29 $0.64)$ respectively.

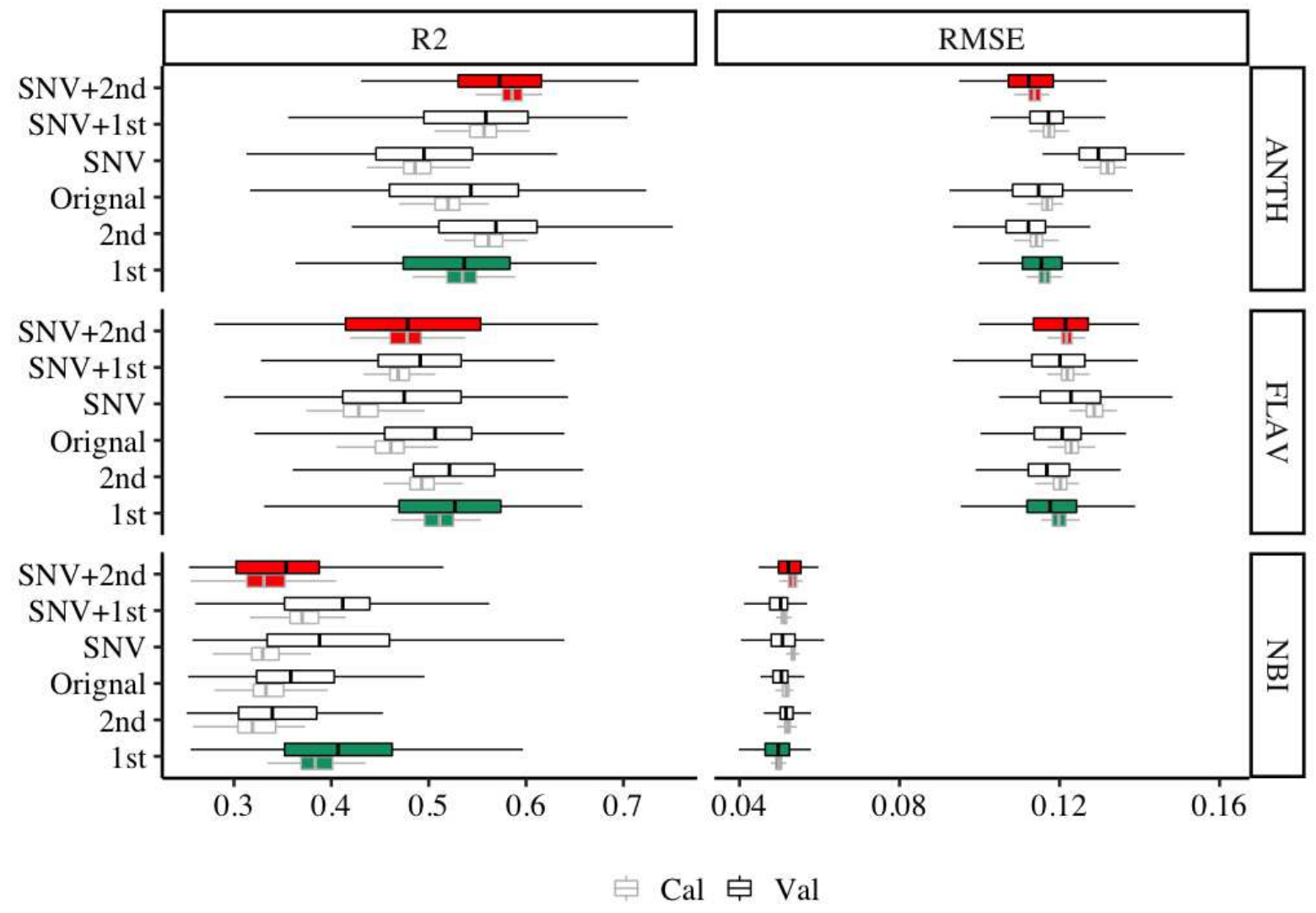

Figure 1 Distribution (95\% confidence intervals) of calibration and validation statistics from 200 simulations of models predicting ANTH, FLAV and NBI with full length NIR spectra. Each model permutation included $80 \%$ of the data for internal calibration and the remaining $20 \%$ for validation. $\mathrm{R}^{2}$ : coefficient of determination of cross-validation; RMSE: root-meansquare error of cross-validation; The black vertical line in each box represents median value, the red colour box represents the $\mathrm{SNV}+2^{\text {nd }}$ model. the green colour box represents the $1^{\text {st }}$ model.

The relationship between the predicted and measured content of Cal and Val datasets by ANTH model with $\mathrm{SNV}+2^{\text {nd }}$ derivative spectra, FLAV and NBI model with $1^{\text {st }}$ derivative spectra was plotted in Figure 2. The error bar represents the prediction error of 200 times per sample. It shows that due to the high accuracy of the ANTH and FLAV models, the predicted values are more correlated with the measured values, while the relationship between predicted and measured values of NBI model is relatively poor. Although the prediction accuracy of each model is different, the prediction error of the Cal and Val data sets is still little. 

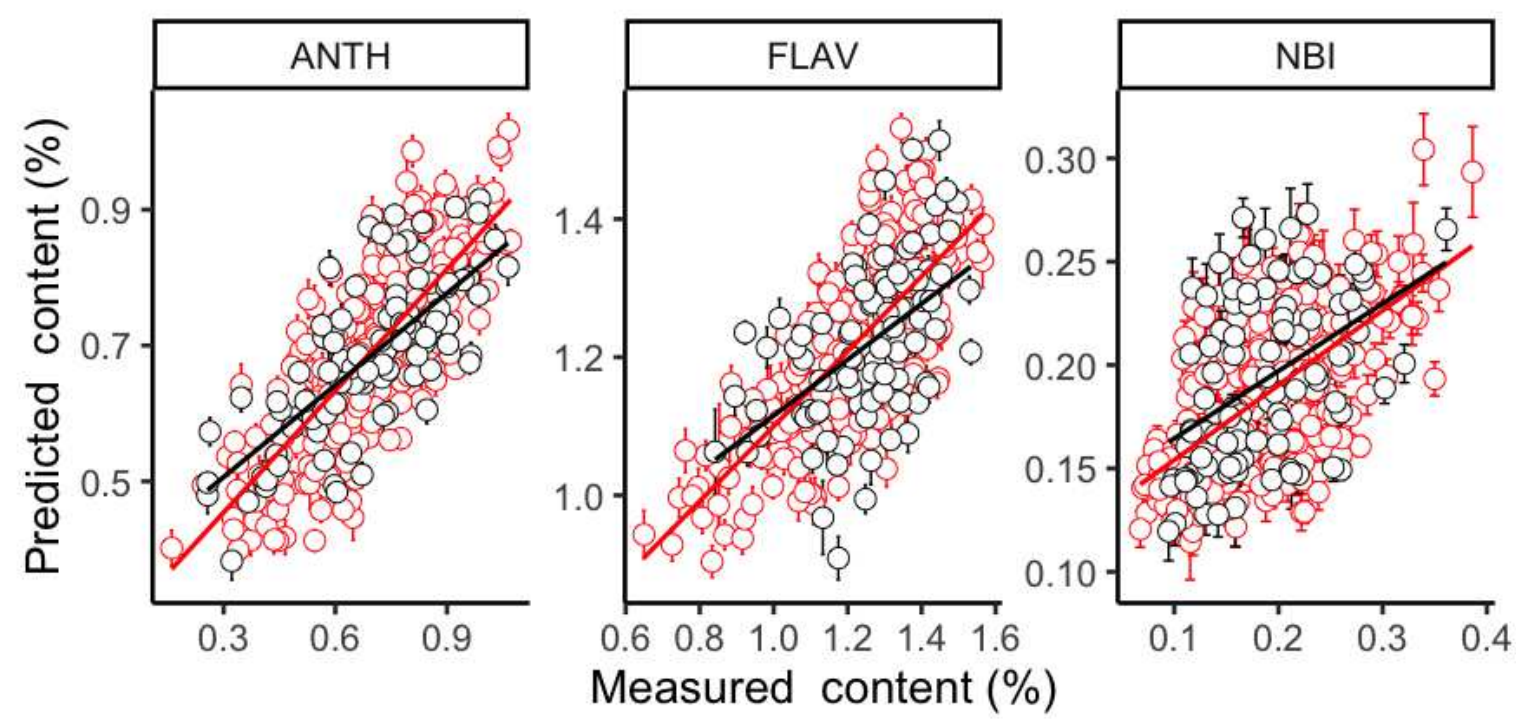

$\ominus$ Cal $\ominus$ Val

Figure 2 Measured and predicted ANTH, FLAV and NBI contents with full length of NIR spectra. Error bars for predicted values represent the standard deviations obtained from the 200 simulated models.

The residual of the best processing spectra model for each leaf trait shows that all of these three models tend to be underpredicted when the measurement value is small. With the rise of the measurement value, the prediction value has the tendency of overprediction. The residual value of ANTH, FLAV and NBI model is between an acceptable range from -0.3 to 0.3 .

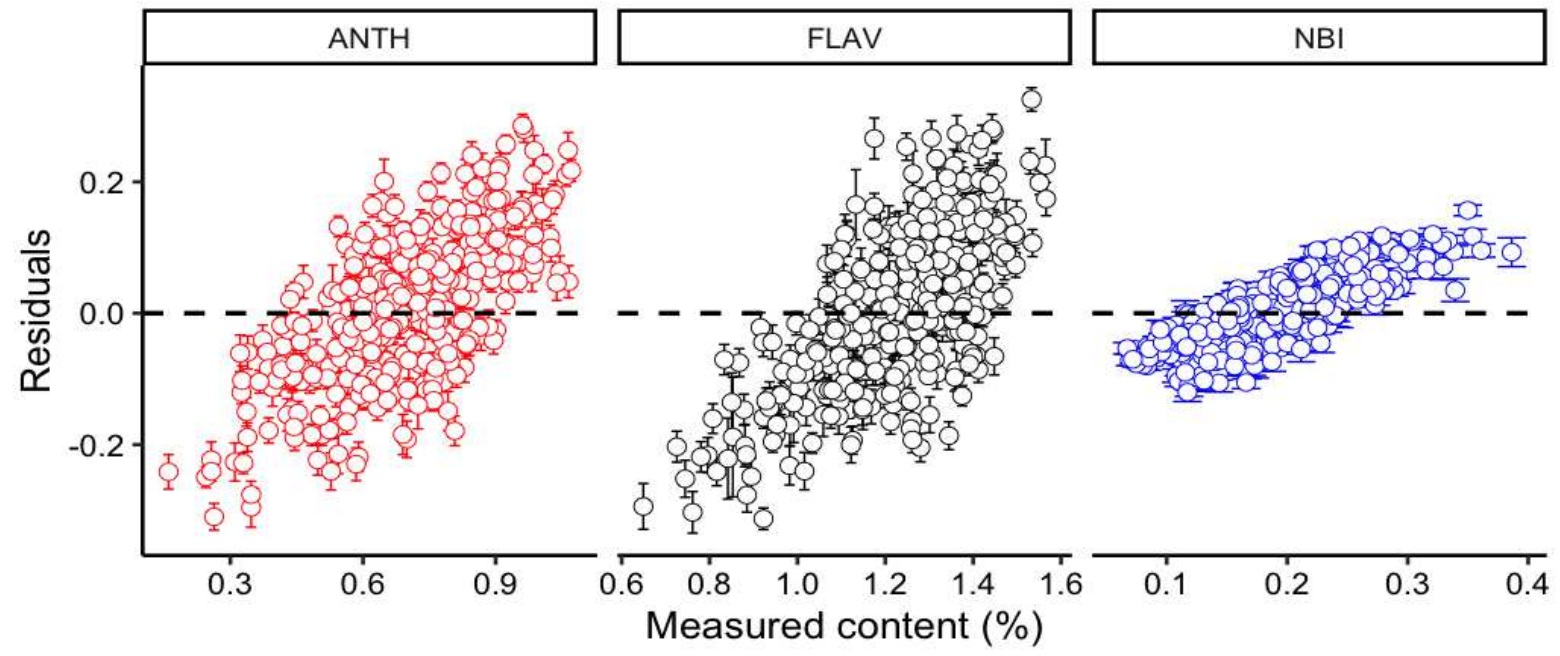

Figure 3 Residuals plotted against measured ANTH, FLAV and NBI with full length of spectra. Error bars for predicted values represent the standard deviations obtained from the 200 simulated models. 


\section{Variable selection and model optimization}

Four types of variable selection methods were compared to test the performance of ANTH, FLAV, and NBI PLSR models (Figure 4). The prediction accuracy of ANTH, FLAV, and NBI PLSR models was enhanced much better than the full-length spectra models by these four different variable selection methods. ANTH model still holds the highest $\mathrm{R}^{2}$ and RMSE value in both Cal and Val data, followed by the FLAV and NBI model. The highest prediction model for ANTH, FLAV and NBI was found through sMC-selected NIR spectra variables with the mean $\mathrm{R}^{2}$ Val of 0.72 (ranged: 0.69 to 0.75 ), 0.58 (ranged from: 0.54 to 0.62 ), 0.44 (ranged from: 0.26 to 0.67 ), and of the mean RMSEVal of $0.10 \%$ (range: $0.09-0.10 \%$ ), $0.11 \%$ (range: $0.10-$ $0.12 \%$ ), $0.04 \%$ (range: $0.04-0.05 \%$ ) respectively. The sMC_PLSR models reached a more stable prediction with less than $16 \%$ of full length of spectra on each leaf trait (Figure 5), and having a similar residual range to the model with full spectral information (Figure 6).

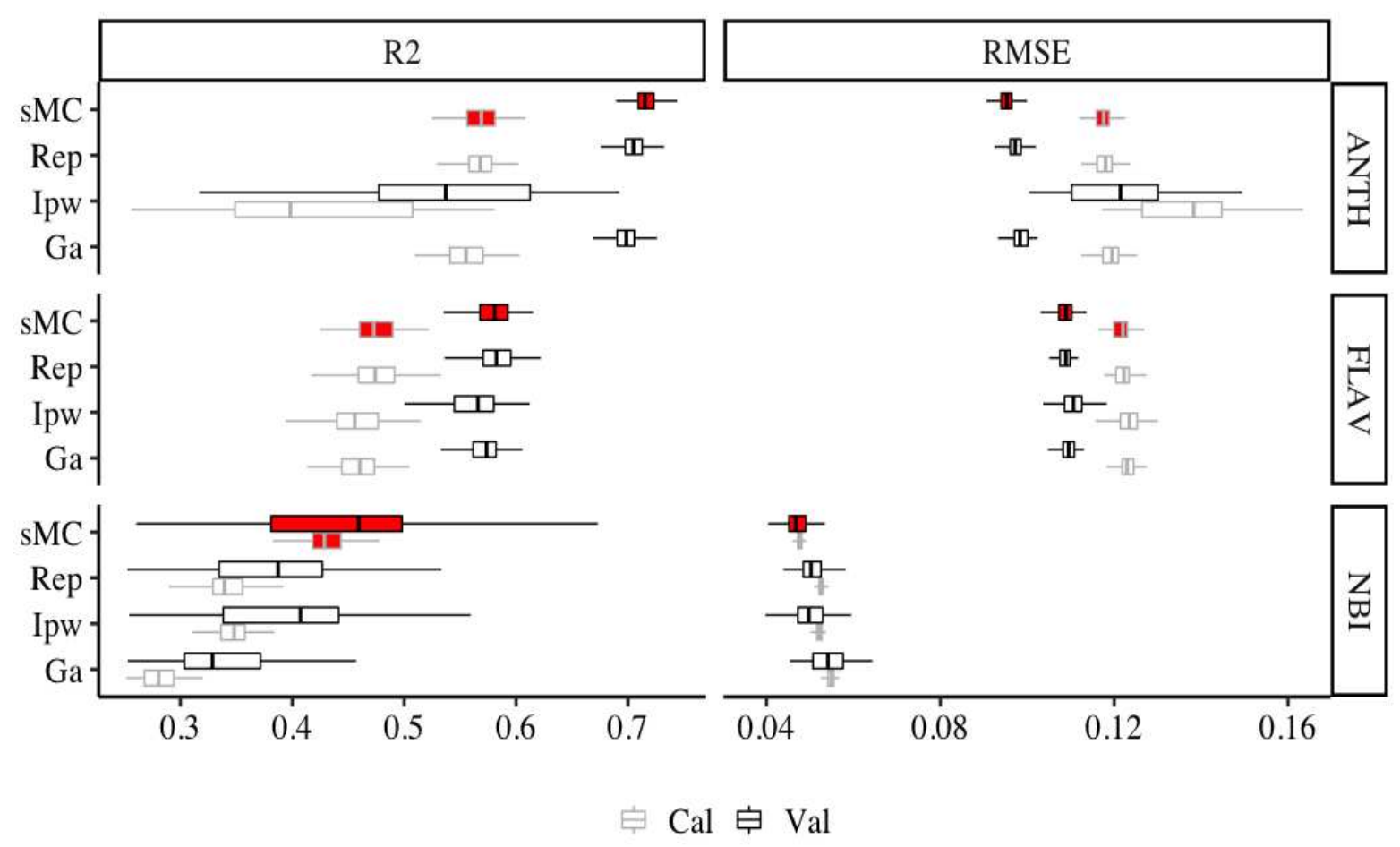

Figure 4 Distribution (95\% confidence intervals) of calibration and validation statistics from 200 simulations for models predicting ANTH, FLAV and NBI contents using sMC, Rep, Ipw and Ga variable selection. Each model permutation included 
$80 \%$ of the data for calibration and the remaining $20 \%$ for validation. $\mathrm{R}^{2}$ : coefficient of determination of cross-validation; RMSE: root-mean-square error of cross-validation; The black vertical line in each box represents median value, the red colour box represents the sMC model.
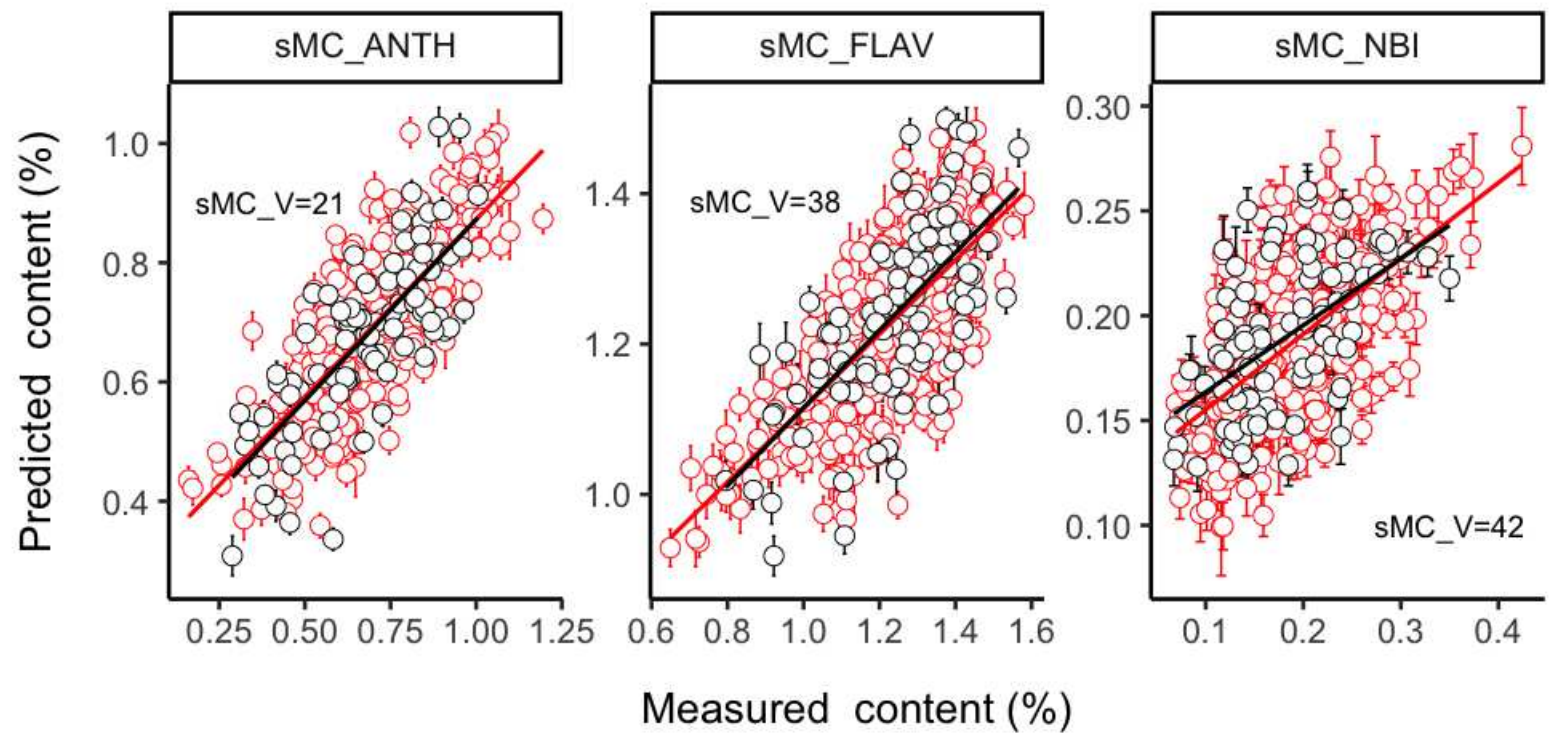

$\ominus$ Cal $\ominus$ Val

Figure 5 Measured and predicted ANTH, FLAV and NBI contents with SMC selected NIR spectra. Error bars for predicted values represent the standard deviations obtained from the 200 simulated models. sMC_V: the total selected number of variables.

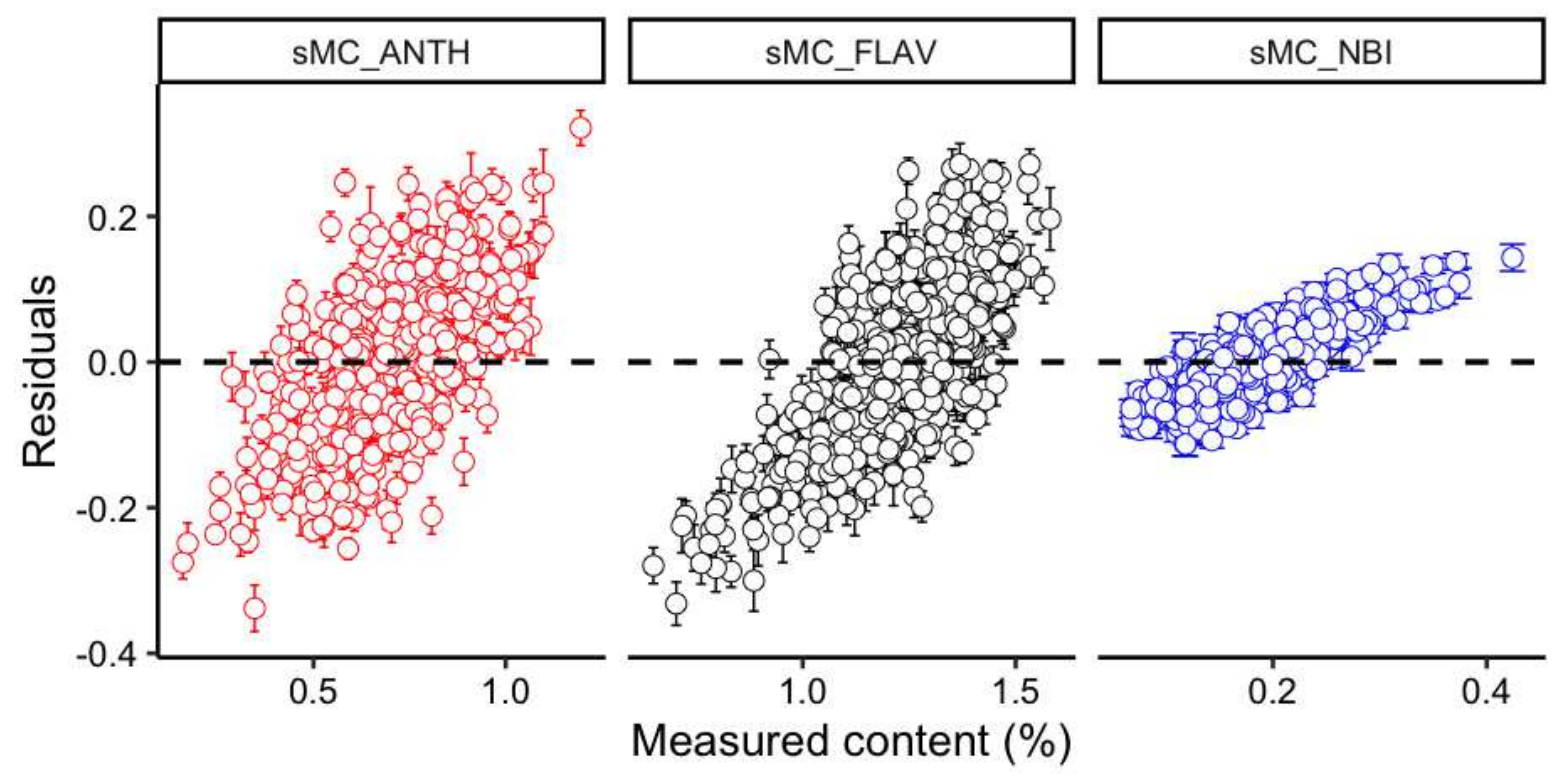

Figure 6 Residuals plotted against measured ANTH, FLAV and NBI with sMC selected spectra. Error bars for predicted values represent the standard deviations obtained from the 200 simulated models. 
Figure 7 displays the important variable information area selected by sMC variable selection method in the ANTH, FLAV and NBI model which conducted 200 times on each model. Even the predicted model of three leaf traits was being run 200 times, sMC variable selection brought out stability for the selected important variable areas with a few relative spectral region in prediction models. The variables at 2060, 2180, 2270, 2330 and 2440nm are considered as the vital roles in the construction of ANTH prediction model. As for FLAV, 1070, 1235, 1950 and $2220 \mathrm{~nm}$ are more important areas. Spectroscopic variables at 1100, 1220, 1465, 1950 and $2220 \mathrm{~nm}$ make a critical difference in the NBI predictive model.

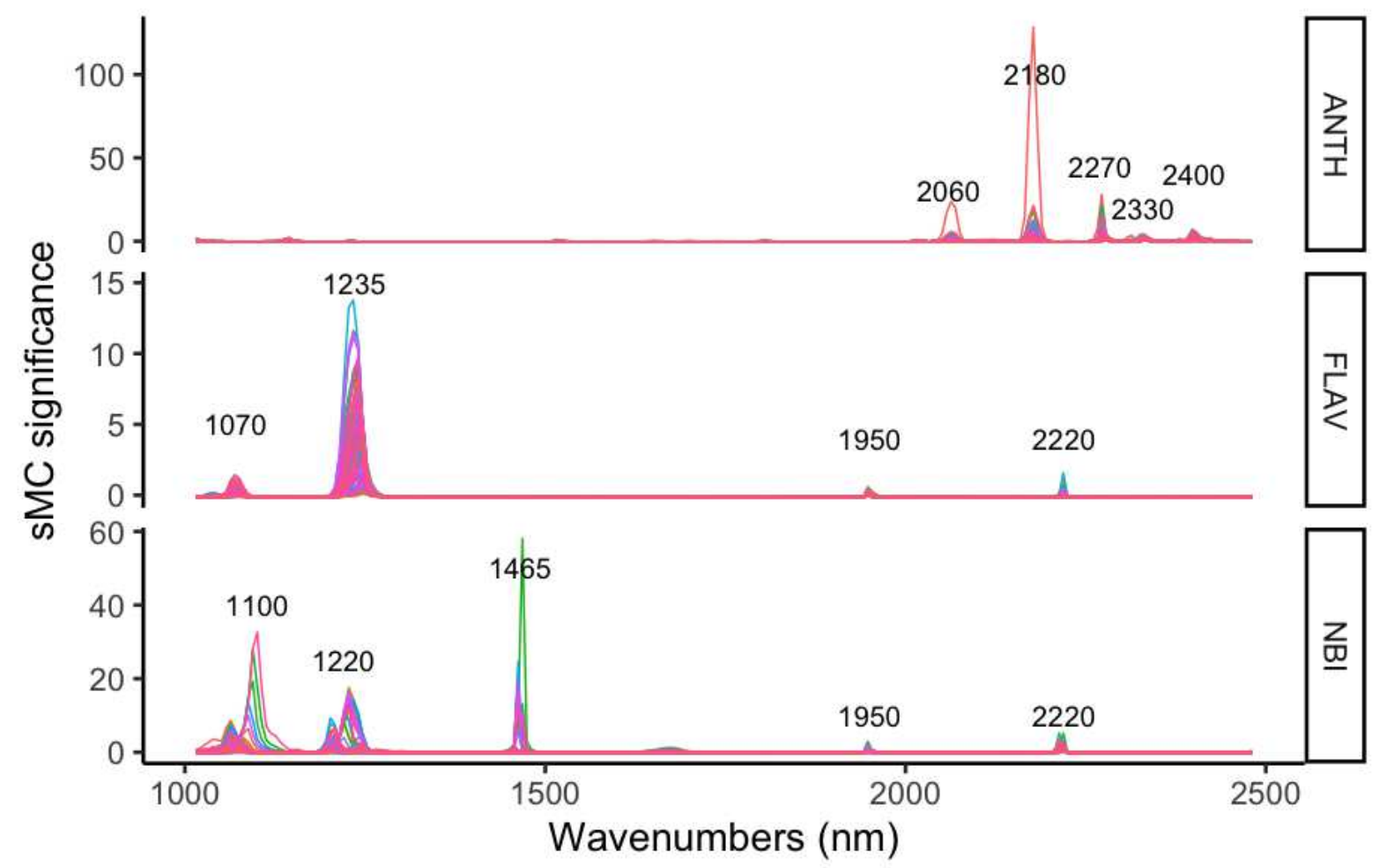

Figure 7 Spectra influence in ANTH, FLAV and NBI models that randomly being conducted 200 times; each line means one time of modelling with sMC variable selection.

\section{Heritability, genetic and phenotypic correlation among traits}

Table 1 shows the correlation (genetic and phenotypic) and heritability of three traits. Leaf ANTH produces the highest heritability of 0.78 , followed by FLAV and NBI with $h^{2}$ of 0.58 and 0.61 respectively. There has no significant genetic and phenotypic correlation between 
ANTH, FLAV and NBI. FLAV was found to have the highest positive genetic correlation with ANTH of a value of 0.36 .

Table 1 The heritability, genetic (above diagonal) and phenotypic correlation (below diagonal) between ANTH, FLAV and NBI traits with standard error between parentheses.

\begin{tabular}{ccccc}
\hline Traits & ANTH & FLAV & NBI & $h^{2}$ \\
ANTH & & $0.36(0.01)$ & $0.11(0.02)$ & $0.78(0.10)$ \\
FLAV & $0.16(0.03)$ & & $0.09(0.01)$ & $0.58(0.11)$ \\
NBI & $0.09(0.01)$ & $0.12(0.01)$ & & $0.61(0.08)$ \\
\hline
\end{tabular}

\section{Family selection}

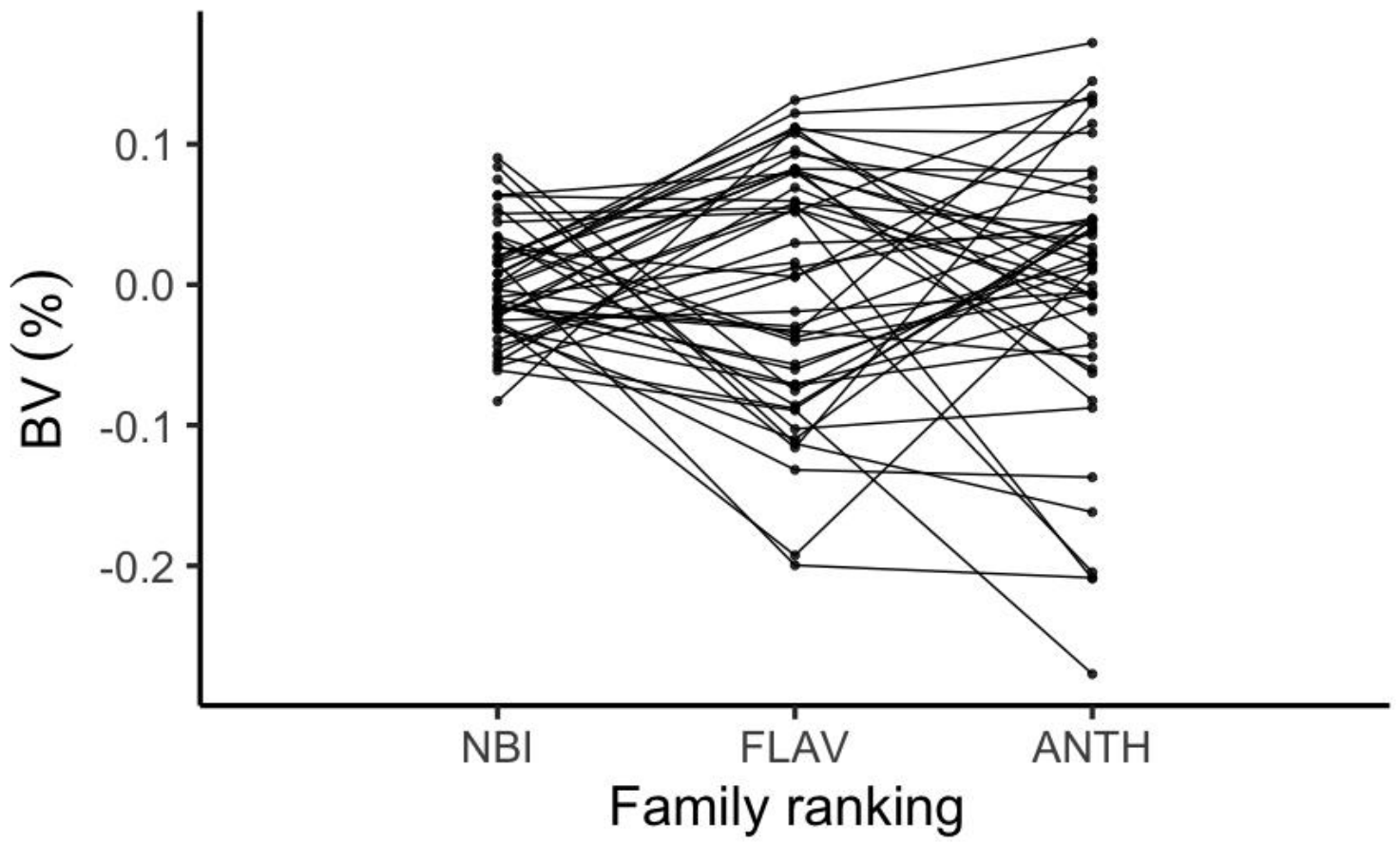

Figure 8 Family ranking for ANTH, FLAV and NBI content in Sassafras tzumu at age 2. Family values are expressed as deviation from each trait mean. BV: Breeding values.

The best models of ANTH, FLAV and NBI were applied to predict the remaining 1000 trees spectra. In total, 1500 trees of 50 families were selected for breeding analysis. Figure 8 shows 
the distribution of three leaf traits in the ranking of breeding value from 50 families. The ranking of three leaf traits in different families is inconsistent as well as a part of families consistently displaying in the breeding value, which explains that it is feasible to make a family selection of ANTH, FLAV and NBI at the same time through genetic selections.

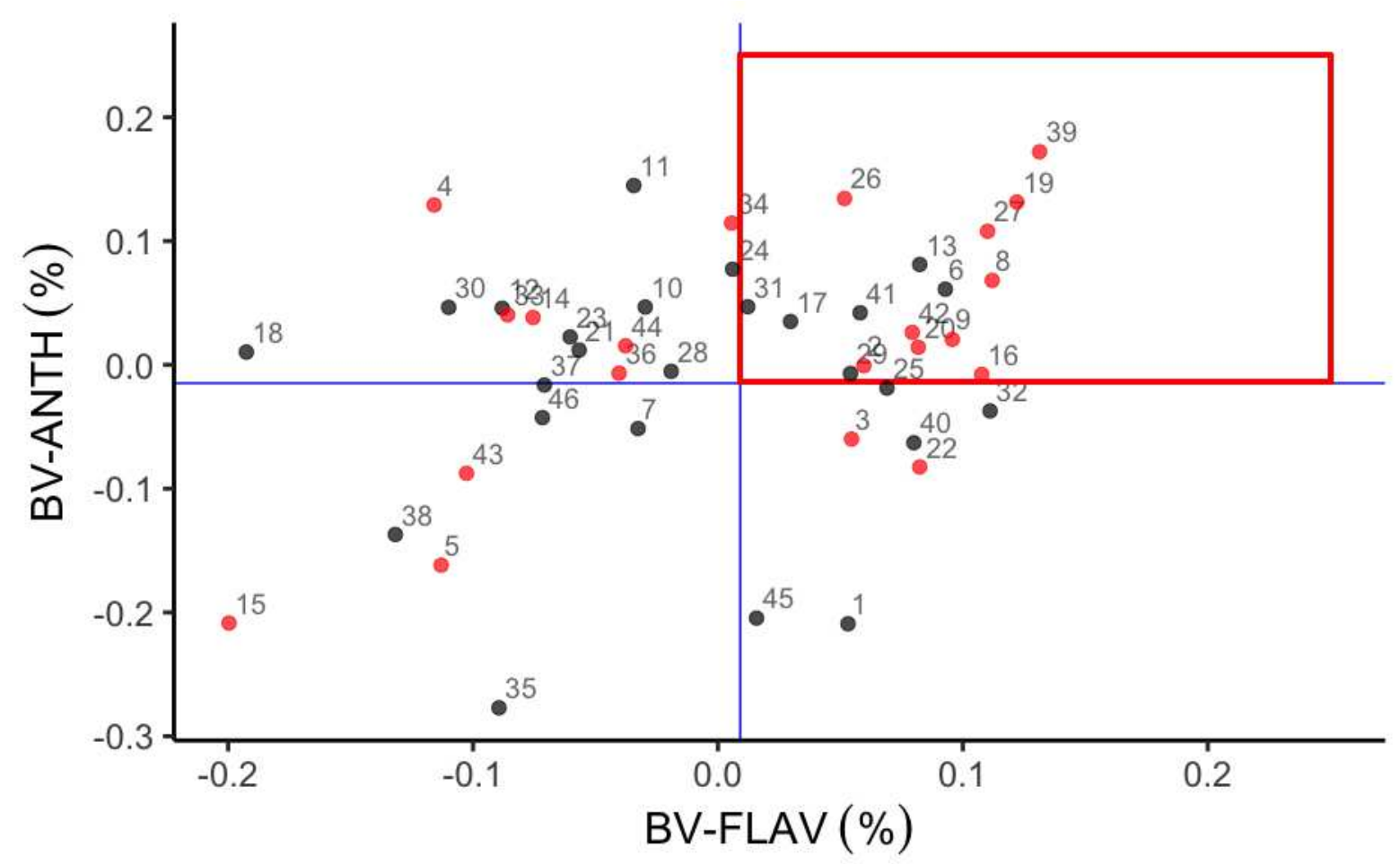

Figure 9 Relationship between ANTH, FLAV and NBI content breeding values of Sassafras tzumu families at age 2. BVANTH: breeding value of ANTH; BV-FLAV: breeding value of FLAV; the blue solid line: the mean value of each trait breeding value; red square: the region that most interesting. The number of each dot: family number.

Figure 9 demonstrates the breeding value distribution of 50 families of three leaf traits. The blue solid lines represent the average of ANTH and FLAV respectively. The families with a higher NBI breeding value than its mean are shown in red, and below the mean is in black. 16 families have high FLAV and ANTH breeding value. 10 families with a high breeding value will be selected If NBI breeding values are required to be above mean. These families can be further taken as genetic family materials for second-generation breeding. 


\section{Discussion}

The health of tree growth is dictated by main factors, such as soil, nutrients, environment, genetic and so on. $\mathrm{N}$ is a key role of nutrient which highly influences the tree growth.

The internal N cycling in trees (Swarts, 2016) is a hot topic in numerous study (Millard and Neilsen, 1989; García-Sánchez et al., 2017; Li and Coleman, 2019). However, the measurement of $\mathrm{N}$ concentration limits the access to the further study. In this study, the fieldbase reflectance spectroscopy is proved to be a useful method to characterize the plant nutrition properties in fresh leaves. The $\mathrm{SNV}+2^{\text {nd }}$ derivative spectra for $\mathrm{ANTH}$, and $1^{\text {st }}$ derivative spectra for FLAV and NBI have been identified to increase the model accuracy when calibrating the PLSR prediction models. Incorporate with spectra variable selection, the model accuracy is significantly improved with less variables for the prediction of leaf nutrition traits. Our model offered a reliable result for predicting the FLAV content in fresh leaf $\left(\mathrm{R}^{2} \mathrm{Val}=0.58\right.$, ranged from: 0.54 to 0.62 ), which was lower than the result reported for fresh Ginkgo biloba leaf in different colors $\left(\mathrm{R}^{2} \mathrm{CAL}=0.82\right.$ and $\left.\mathrm{RMSE}=2.62 \%\right)$ (Shi et al., 2012). The variability lessened by small range of NBI value lead to an inefficient prediction (Blanco and Villarroya, 2002).

Conversely, our result of the prediction of ANTH content illustrates a suitable accuracy than the other two leaf traits, with a mean $\mathrm{R}^{2}$ val of 0.72 (range: $0.69-0.75$ ) and a mean of RMSEval $=0.09 \%$ (range: $0.09-0.10 \%$ ). Similar result was discovered in wine grapes by NIR hyperspectral imaging and PLSR model, which gave $\mathrm{R}^{2}$ of 0.84 and RMSEP of $0.013 \%$ for estimating ANTH content.

A robust statistical methodology for model calibration which was first conducted by Couture et al. (2016) was carried out to predict plant leaf secondary metabolites with reflectance spectroscopy. It was being run 200 randomized simulations for calibrating the models to provide an estimation of the model uncertainty and overall stability (Figures 1-7). It is similar 
to our previous study which takes use of filed spectroscopy to predict the leaf colour and chlorophyll content (Li et al., 2019). Random sampling (Quentin et al., 2017) and KennardStone sampling algorithm (Li et al., 2018b) in other studies, which sample only once for model calibration, may cause instability for model prediction. Thus, we highly recommend to use this methodology for model calibration and validation on NIR analysis.

The NIR spectra involves not only the favourable information but noise and irrelevant information which will encumbrance the model accuracy of prediction. Therefore, variable selection is regarded as an efficient way to find out the most important wavelengths which contributes the minimum error for model calibration and helps to reduce the model processing time for spectral models. Variables in the spectrum play a key role in the predictive accuracy of the model. The spectral information is extensive along with the relevant and irrelevant information, both of which will overlap to interfere the model construction of the useful information and the PLSR model with a specific trait (Workman Jr and Weyer, 2012). Thus, it is vital to screen important variables for spectral information. In this study, four variable selection methods were compared to pick the best variable selection method. It shows that the sMC-PLSR model efficiently identified the key wavelengths and enables us to select a small set of variables to yield a promising and robust calibrated model for the prediction of ANTH, FLAV and NBI. Our results support the research announced by Li and Altaner (2018), who successfully took the sMC variable selection method to improve the accuracy of an NIR calibration model to predict concentrations in extracts of heartwood of Eucalyptus bosistoana trees, and Li et al. (2019) who found that sMC selection algorithm held the advantage of finding the most relevant variables for the prediction of leaf chlorophyll content and colour parameters. Some studies also states that significance multivariate correlation (sMC) (Tran et al., 2014) is a positive algorithm to remove confounding effects from NIR calibrations (Wijewardane et al., 2016). 
Several important variables which are related to the ANTH, FLAV, and NBI have been selected similarly in each model, including the range at 2060, 2180, 2270, 2330 and $2440 \mathrm{~nm}$ for ANTH, 1070, 1235, 1950, $2220 \mathrm{~nm}$ for FLAV, and 1100, 1220, 1465, 1950, $2220 \mathrm{~nm}$ for NBI respectively. As reported by Ramirez et al. (2015), the regions around 2060, 2180, 2270, 2330 and $2440 \mathrm{~nm}$ are mostly associated with $\mathrm{O}-\mathrm{H}$ and $\mathrm{C}-\mathrm{H}$ stretching vibrations as well as the starch and sugar (Decruyenaere et al., 2012). However, in our study, these regions have been ignored. The regions around 1070, 1100, 1220, $1235 \mathrm{~nm}$ are mainly assigned to the $1^{\text {st }}$ overtones of $\mathrm{C}-\mathrm{H}$ combination bands and $1^{\text {st }}$ and $2^{\text {nd }}$ overtones of $\mathrm{O}-\mathrm{H}$ and $\mathrm{N}-\mathrm{H}$ stretching vibrations, while the bands around $1465 \mathrm{~nm}$ are mostly related to the $1^{\text {st }}$ overtones of $\mathrm{O}-\mathrm{H}$ stretching vibration, both of which are associated with starch and protein (Curran, 1989; Kokaly, 2001; De Bei et al., 2017). In NIR spectra, water has a wide absorbance region which is a major influence on the other chemical information because of spectra overlap. In our study, the band around $1950 \mathrm{~nm}$ related to the water has less contribution to the FLAV and NBI model but no influence on the ANTH model. It probably influences the accuracy of model for the prediction of FLAV and NBI. Correlational study was found by Min et al. (2006), who stressed that the regions of 1910 and $1938 \mathrm{~nm}$ highly related to water might have a strong impact on the $\mathrm{N}$ concentration prediction.

Trees $\mathrm{N}$ internal cycling is considered as one of the major ecology factors for tree growth and is an augment for the tree uptake of soil N (Millard, 1989). In addition, it also helps to understand numerous aspects of plant ecology, for instance, to evaluate the effect of the $\mathrm{N}$ storage and remobilization in different part tissues of trees in relation to current demands for growth (Schneider et al., 1996), to find out the role of $\mathrm{N}$ on growth stress, the relationship with N deposition in forest (Gundersen, 1991; Gundersen et al., 1998) and the relationship with dynamics of carbon recourse in trees (Villar-Salvador et al., 2015; Han and Kabeya, 2017). Our fast and accurate measurement of N index, including ANTH, FLAV and NBI traits of trees 
with NIR spectroscopy provides an advanced way for the study of $\mathrm{N}$ internal cycling and allows to quickly measure large number of samples.

In this study, we continue to use the coefficients of $1 / 2.5$ for the calculation of heritability of ANTH, FLAV and NBI traits based on our previous study to avoid the assembling of halfsiblings and inbreeding effects. (Li et al., 2019). The moderate heritability of ANTH, FLAV and NBI was found, with the value of $h^{2}$ ranging from 0.61 to 0.78 . The leaf ANTH heritability of 0.78 in our study is similar to the result found by Yihu et al. (2009) who figured out the anthocyanin content heritability ranging from 0.79 to 0.91 in leaves of chili pepper higher than 0.29 reported in the leaf of Aspen (Populus tremula L.) (Robinson et al., 2012). For FLAV, a significant high rang of heritability from 0.94 to 0.99 was reported in the leave of Ginkgo Trees (Zhang et al., 2017) which was much higher than our study $\left(h^{2}=0.58\right)$. It indicates that genetic control capacity is different between species even the same traits. Our study proves there is also a potential for the selection for NBI traits in breeding programs while with less study on the estimation of NBI heritability.

The consistence of families ranking of ANTH, FLAV and NBI indicates that the selection for a good leaf nutrition tree is workable, and the selection of qualified nutrition plant is supposed to involve multiple traits, which will afford a stable inheritance.

\section{Conclusion}

In conclusion, NIR spectroscopy is potentially taken to estimate the nutrition related traits by fresh leaf. Although our models do not perform a higher accuracy for ANTH, FLAV and NBI, the residuals shown that the prediction error are small. This should not affect the availability in tree breeding programs, cause the selections can be based on relative prediction value. Our study provide an alternative way for the $\mathrm{N}$ index traits and open a door to the efficient analysis of the internal $\mathrm{N}$ cycling in trees. The pre-processing method and variable selection much influence the performance of model prediction. Our study found that by using of $1^{\text {st }}$ and SNV+ 
$2^{\text {nd }}$ derivative spectra processing method and sMC variable selection algorithm, the PLSR models have been highly improved. In addition, the repeated spectral statistical methodology that we applied provided an efficient way to deal with variation in calibration data and generate information on the response of plant nutrition traits with NIR spectra. NIR model serves as an efficient tool for the estimation of genetic parameters and breeding selection in high throughput way to improve the leaf traits quality.

\section{Declarations}

\section{Ethics approval and consent to participate}

Not applicable.

\section{Consent for publication}

Not applicable.

\section{Availability of data and material}

Not applicable.

\section{Competing interests}

The authors declare that there is no conflict of interest.

\section{Funding}

This work was funded by Zhejiang Science and Technology Major Program on Agricultural (Forestry) New Variety Breeding (2016C02056-10).

\section{Authors' contributions}

Yanjie Li designed the study, conducted the experiment, analysed the data and wrote the manuscript. Jun Liu, Yang Sun, Wenjian Liu and Zifeng Tan conducted lab experiments and 
modified the manuscript. Jingmin Jiang supervised the experiments at all stages and reviewed the manuscript. All authors have read and approved the final manuscript.

\section{Acknowledgements}

Not applicable.

\section{Authors' information}

Not applicable.

\section{Reference:}

Asner, G.P., Martin, R.E., Knapp, D.E., Tupayachi, R., Anderson, C., Carranza, L., Martinez, P., Houcheime, M., Sinca, F., Weiss, P., 2011. Spectroscopy of canopy chemicals in humid tropical forests. Remote Sensing of Environment 115, 3587-3598.

Babst, B.A., Coleman, G.D., 2018. Seasonal nitrogen cycling in temperate trees: transport and regulatory mechanisms are key missing links. Plant Sci. 270, 268-277.

Barnes, R., Dhanoa, M.S., Lister, S.J., 1989. Standard normal variate transformation and detrending of near-infrared diffuse reflectance spectra. Appl. Spectrosc. 43, 772-777.

Bates, D., Maechler, M., Bolker, B., Walker, S., Christensen, R.H.B., Singmann, H., Dai, B., Grothendieck, G., Green, P., Bolker, M.B., 2015. Package 'lme4'. Convergence 12, 2.

Blanco, M., Villarroya, I.N.I.R., 2002. NIR spectroscopy: a rapid-response analytical tool. TrAC, Trends Anal. Chem. 21, 240-250.

Bokobza, L., 2002. Origin of near-infrared absorption bands. Wiley-VCH.

Bolster, K.L., Martin, M.E., Aber, J.D., 1996. Determination of carbon fraction and nitrogen concentration in tree foliage by near infrared reflectances: A comparison of statistical methods. Canadian journal of forest research 26, 590-600. 
Borges, D.L.G., Holcombe, J.A., 2017. Graphite Furnace Atomic Absorption Spectrometry. Encyclopedia of Analytical Chemistry, 1-20.

Caliari, Í.P., Barbosa, M.H., Ferreira, S.O., Teófilo, R.F., 2017. Estimation of cellulose crystallinity of sugarcane biomass using near infrared spectroscopy and multivariate analysis methods. Carbohydr. Polym. 158, 20-28.

Cánovas, F.M., Cañas, R.A., de la Torre, F.N., Pascual, M.B., Castro-Rodríguez, V., Avila, C., 2018. Nitrogen metabolism and biomass production in forest trees. Frontiers in Plant Science $9,1449$.

Cooke, J.E., Weih, M., 2005. Nitrogen storage and seasonal nitrogen cycling in Populus: bridging molecular physiology and ecophysiology. New Phytol. 167, 19-30.

Couture, J.J., Singh, A., Rubert-Nason, K.F., Serbin, S.P., Lindroth, R.L., Townsend, P.A., 2016. Spectroscopic determination of ecologically relevant plant secondary metabolites. Methods Ecol Evol 7, 1402-1412.

Croft, H., Chen, J., 2017. Leaf pigment content. Reference Module in Earth Systems and Environmental Sciences. Oxford: Elsevier Inc, 1-22.

Curran, P.J., 1989. Remote sensing of foliar chemistry. Remote Sensing of Environment 30, 271-278.

Cyr, D., Bewley, J., Dumbroff, E., 1990. Seasonal dynamics of carbohydrate and nitrogenous components in the roots of perennial weeds. Plant, Cell \& Environment 13, 359-365.

De Bei, R., Fuentes, S., Sullivan, W., Edwards, E.J., Tyerman, S., Cozzolino, D., 2017. Rapid measurement of total non-structural carbohydrate concentration in grapevine trunk and leaf tissues using near infrared spectroscopy. Computers and electronics in agriculture 136, 176183. 
Decruyenaere, V., Clément, C., Agneessens, R., Losseau, C., Stilmant, D., 2012. Development of near-infrared spectroscopy calibrations to quantify starch and soluble sugar content in the roots of Rumex obtusifolius. Weed Res. 52, 1-5.

Eom, S.-H., Jin, C.-W., Park, H.-J., Kim, E.-H., Chung, I.-M., Kim, M.-J., Yu, C.-Y., Cho, D.H., 2007. Far infrared ray irradiation stimulates antioxidant activity in Vitis flexuosa THUNB. berries. Korean Journal of Medicinal Crop Science 15, 319-323.

Evans, J.R., 1983. Nitrogen and photosynthesis in the flag leaf of wheat (Triticum aestivum L.). Plant Physiol. 72, 297-302.

Famula, R.A., Richards, J.H., Famula, T.R., Neale, D.B., 2019. Association genetics of carbon isotope discrimination and leaf morphology in a breeding population of Juglans regia L. Tree Genet. Genom. 15, 6.

Fernández, J.L., Sáez, F., Castro, E., Manzanares, P., Ballesteros, M., Negro, M.J., 2019. Determination of the Lignocellulosic Components of Olive Tree Pruning Biomass by Near Infrared Spectroscopy. Energies 12, 2497.

Forina, M., Casolino, C., Pizarro Millan, C., 1999. Iterative predictor weighting (IPW) PLS: a technique for the elimination of useless predictors in regression problems. Journal of Chemometrics: A Journal of the Chemometrics Society 13, 165-184.

Forina, M., Oliveri, P., Bagnasco, L., Simonetti, R., Casolino, M., Grifi, F.N., Casale, M., 2015. Artificial nose, NIR and UV-visible spectroscopy for the characterisation of the PDO Chianti Classico olive oil. Talanta. 144, 1070-1078.

García-Sánchez, F., Simón-Grao, S., Gimeno, V., Martínez-Nicolás, J.J., Srivastava, A., 2017. 7 Irrigation and Fertilization Management in Lime Trees. The Lime: Botany, Production and Uses, 91. 
Garriga, M., Retamales, J.B., Romero-Bravo, S., Caligari, P.D., Lobos, G.A., 2014. Chlorophyll, anthocyanin, and gas exchange changes assessed by spectroradiometry in Fragaria chiloensis under salt stress. Journal of integrative plant biology 56, 505-515.

Gebreselassie, M.N., Ader, K., Boizot, N., Millier, F., Charpentier, J.-P., Alves, A., Simões, R., Rodrigues, J.C., Bodineau, G., Fabbrini, F., Sabatti, M., Bastien, C., Segura, V., 2017. Nearinfrared spectroscopy enables the genetic analysis of chemical properties in a large set of wood samples from Populus nigra (L.) natural populations. Ind. Crops. Prod. 107, 159-171.

Guillemain, A., Dégardin, K., Roggo, Y., 2017. Performance of NIR handheld spectrometers for the detection of counterfeit tablets. Talanta. 165, 632-640.

Gundersen, P., 1991. Nitrogen deposition and the forest nitrogen cycle: role of denitrification. Forest ecology and management 44, 15-28.

Gundersen, P., Emmett, B.A., Kjønaas, O.J., Koopmans, C.J., Tietema, A., 1998. Impact of nitrogen deposition on nitrogen cycling in forests: a synthesis of NITREX data. Forest Ecology and management 101, 37-55.

Han, Q., Kabeya, D., 2017. Recent developments in understanding mast seeding in relation to dynamics of carbon and nitrogen resources in temperate trees. Ecological research 32, 771-778. Hardin, J.A., Smith, M.W., Weckler, P.R., Cheary, B.S., 2012. In situ measurement of pecan leaf nitrogen concentration using a chlorophyll meter and vis-near infrared multispectral camera. HortScience 47, 955-960.

Hu, X.-F., Wu, A.-Q., Wang, F.-C., Chen, F.-S., 2019. The effects of simulated acid rain on internal nutrient cycling and the ratios of $\mathrm{Mg}, \mathrm{Al}, \mathrm{Ca}, \mathrm{N}$, and $\mathrm{P}$ in tea plants of a subtropical plantation. Environmental monitoring and assessment 191, 99.

Huang, J., Peng, S., 2004. Comparison and standardization among chlorophyll meters in their readings on rice leaves. Plant production science 7, 97-100. 
Inagaki, T., Yonenobu, H., Asanuma, Y., Tsuchikawa, S., 2018. Determination of physical and chemical properties and degradation of archeological Japanese cypress wood from the Tohyamago area using near-infrared spectroscopy. J Wood Sci. 64, 347-355.

Jiang aiping, Liu jun, Jiang jingmin, 2016. Relationships of Leaf Color and Pigment and Nutrient Elements in Senescing Leaves of Sassafras tsumu. For Res 29, 362.

Jin, X., Chen, X., Shi, C., Li, M., Guan, Y., Yu, C.Y., Yamada, T., Sacks, E.J., Peng, J., 2017. Determination of hemicellulose, cellulose and lignin content using visible and near infrared spectroscopy in Miscanthus sinensis. Bioresour. Technol. 241, 603-609.

Kokaly, R.F., 2001. Investigating a physical basis for spectroscopic estimates of leaf nitrogen concentration. Remote Sensing of Environment 75, 153-161.

Li, G., Coleman, G.D., 2019. Nitrogen storage and cycling in trees. In, Adv. Bot. Res. Elsevier, pp. 127-155.

Li, Y., Altaner, C., 2018. Predicting extractives content of Eucalyptus bosistoana F. Muell. Heartwood from stem cores by near infrared spectroscopy. Spectrochimica Acta Part A: Molecular and Biomolecular Spectroscopy 198, 78-87.

Li, Y., Apiolaza, L.A., Altaner, C., 2018a. Genetic variation in heartwood properties and growth traits of Eucalyptus bosistoana. Eur. J. For. Res. 137, 565-572.

Li, Y., Sun, Y., Jiang, J., Liu, J., 2019. Spectroscopic determination of leaf chlorophyll content and color for genetic selection on Sassafras tzumu. Plant Methods 15, 73.

Li, Z., Li, C., Gao, Y., Ma, W., Zheng, Y., Niu, Y., Guan, Y., Hu, J., 2018b. Identification of oil, sugar and crude fiber during tobacco (Nicotiana tabacum L.) seed development based on near infrared spectroscopy. Biomass Bioenergy 111, 39-45.

Liang, L., Wei, L., Fang, G., Xu, F., Deng, Y., Shen, K., Tian, Q., Wu, T., Zhu, B., 2020. Prediction of holocellulose and lignin content of pulp wood feedstock using near infrared 
spectroscopy and variable selection. Spectrochimica Acta Part A: Molecular and Biomolecular Spectroscopy 225, 117515.

Liu, X., Liu, C., Shi, Z., Chang, Q., 2019. Comparison of prediction power of three multivariate calibrations for estimation of leaf anthocyanin content with visible spectroscopy in Prunus cerasifera. PeerJ 7, e7997.

Malagoli, P., Laine, P., Rossato, L., Ourry, A., 2005. Dynamics of nitrogen uptake and mobilization in field-grown winter oilseed rape (Brassica napus) from stem extension to harvest: I. Global $\mathrm{N}$ flows between vegetative and reproductive tissues in relation to leaf fall and their residual N. Annals of botany 95, 853-861.

Malegori, C., Marques, E.J.N., de Freitas, S.T., Pimentel, M.F., Pasquini, C., Casiraghi, E., 2017. Comparing the analytical performances of Micro-NIR and FT-NIR spectrometers in the evaluation of acerola fruit quality, using PLS and SVM regression algorithms. Talanta 165, 112-116.

Mancini, M., Rinnan, Å., Pizzi, A., Mengarelli, C., Rossini, G., Duca, D., Toscano, G., 2018. Near infrared spectroscopy for the discrimination between different residues of the wood processing industry in the pellet sector. Fuel 217, 650-655.

Markwell, J., Osterman, J.C., Mitchell, J.L., 1995. Calibration of the Minolta SPAD-502 leaf chlorophyll meter. Photosynthesis Res. 46, 467-472.

Mehmood, T., Liland, K.H., Snipen, L., Sæbø, S., 2012. A review of variable selection methods in partial least squares regression. Chemometrics Intellig. Lab. Syst. 118, 62-69.

Mevik, B., Wehrens, R., Hovde, L., 2015. Partial Least Squares and Principal Component Regression. R package version 2.5-0. In.

Millard, P., 1989. Effect of nitrogen supply on growth and internal nitrogen cycling within deciduous trees. In, Annales des Sciences forestières. EDP Sciences, pp. 666s-668s. 
Millard, P., 1996. Ecophysiology of the internal cycling of nitrogen for tree growth. Zeitschrift für Pflanzenernährung und Bodenkunde 159, 1-10.

Millard, P., Neilsen, G., 1989. The influence of nitrogen supply on the uptake and remobilization of stored $\mathrm{N}$ for the seasonal growth of apple trees. Ann. Bot. 63, 301-309.

Millard , P., Proe, M.F., 1993. Nitrogen uptake, partitioning and internal cycling in Picea sitchensis (Bong.) Carr. as influenced by nitrogen supply. New Phytologist 125, 113-119.

Min, M., Lee, W.S., Kim, Y.H., Bucklin, R.A., 2006. Nondestructive detection of nitrogen in Chinese cabbage leaves using VIS-NIR spectroscopy. HortScience 41, 162-166.

Monje, O.A., Bugbee, B., 1992. Inherent limitations of nondestructive chlorophyll meters: a comparison of two types of meters. HortScience 27, 69-71.

Moreau, B., Gardiner, E.S., Stanturf, J.A., Fisher, R.K., 2004. Estimating leaf nitrogen of eastern cottonwood trees with a chlorophyll meter. Gen Tech Rep SRS-71. US Department of Agriculture, Forest Service, Southern Research Station, Asheville, NC, 487-491.

Naing, A.H., Park, K.I., Ai, T.N., Chung, M.Y., Han, J.S., Kang, Y.-W., Lim, K.B., Kim, C.K., 2017. Overexpression of snapdragon Delila (Del) gene in tobacco enhances anthocyanin accumulation and abiotic stress tolerance. BMC Plant Biol. 17, 65.

Nambiar, E.K.S., Fife, D.N., 1991. Nutrient retranslocation in temperate conifers. Tree Physiol 9, 185-207.

Padilla, F.M., Peña-Fleitas, M.T., Gallardo, M., Thompson, R.B., 2014. Evaluation of optical sensor measurements of canopy reflectance and of leaf flavonols and chlorophyll contents to assess crop nitrogen status of muskmelon. European journal of agronomy 58, 39-52.

Park, S., Kim, J., Yeon, S., Yang, S., Yeo, H., Choi, I., 2018. Rapid Prediction of the Chemical Information of Wood Powder from Softwood Species Using Near-Infrared Spectroscopy. BioResources 13, 2440-2451. 
Paul, V., Sharma, L., Kumar, R., Pandey, R., Meena, R., 2017. Estimation of chlorophylls/photosynthetic pigments-their stability is an Indicator of crop plant tolerance to abiotic stresses. Manual of ICAR Sponsored Training Programme for Technical Staff of ICAR Institutes on "Physiological Techniques to Analyze the Impact of Climate Change on Crop Plants", 8 .

Payne, R.J., Dise, N.B., Field, C.D., Dore, A.J., Caporn, S.J., Stevens, C.J., 2017. Nitrogen deposition and plant biodiversity: past, present, and future. Front. Ecol. Environ. 15, 431-436. Press, W.H., Teukolsky, S.A., 1990. Savitzky-Golay smoothing filters. Computers in Physics 4, 669-672.

Quentin, A.G., Rodemann, T., Doutreleau, M.F., Moreau, M., Davies, N.W., Millard, P., 2017. Application of near-infrared spectroscopy for estimation of non-structural carbohydrates in foliar samples of Eucalyptus globulus Labilladière. Tree physiology 37, 131-141.

R Core Team, 2017. R: A Language and Environment for Statistical Computing. In, R Foundation for Statistical Computing, Vienna, Austria.

Ramirez, J.A., Posada, J.M., Handa, I.T., Hoch, G., Vohland, M., Messier, C., Reu, B., 2015. Near-infrared spectroscopy (NIRS) predicts non-structural carbohydrate concentrations in different tissue types of a broad range of tree species. Methods in Ecology and Evolution 6, 1018-1025.

Rivero-Villar, A., Templer, P.H., Parra-Tabla, V., Campo, J., 2018. Differences in nitrogen cycling between tropical dry forests with contrasting precipitation revealed by stable isotopes of nitrogen in plants and soils. Biotropica 50, 859-867.

Robinson, K.M., Ingvarsson, P.K., Jansson, S., Albrectsen, B.R., 2012. Genetic variation in functional traits influences arthropod community composition in aspen (Populus tremula L.). PLoS One 7. 
Schneider, S., GEßLER, A., Weber, P., von Sengbusch, D., Hanemann, U., Rennenberg, H., 1996. Soluble N compounds in trees exposed to high loads of N: a comparison of spruce (Picea abies) and beech (Fagus sylvatica) grown under field conditions. New Phytologist 134, 103114.

Shi, J.-y., Zou, X.-b., Zhao, J.-w., Mel, H., Wang, K.-1., Wang, X., Chen, H., 2012. Determination of total flavonoids content in fresh Ginkgo biloba leaf with different colors using near infrared spectroscopy. Spectrochimica Acta Part A: Molecular and Biomolecular Spectroscopy 94, 271-276.

Sinclair, T., Horie, T., 1989. Leaf nitrogen, photosynthesis, and crop radiation use efficiency: a review. Crop Sci. 29, 90-98.

Srinivasan, A., 2006. Handbook of precision agriculture: principles and applications. CRC press.

Stevens, A., Ramirez-Lopez, L., 2014. An introduction to the prospectr package. R Package Vignette, Report No.: R Package Version 0.13.

Strack, D., Wray, V., 1989. Anthocyanins. In, Methods in plant biochemistry. Elsevier, pp. $325-356$.

Swarts, N., 2016. Precision fertigation for improved apple orchard productivity. In, 2016 Future Orchards National Tour, pp. 1-25.

Tran, T.N., Afanador, N.L., Buydens, L.M., Blanchet, L., 2014. Interpretation of variable importance in partial least squares with significance multivariate correlation (sMC). Chemometrics Intellig. Lab. Syst. 138, 153-160.

Tremblay, N., Wang, Z., Cerovic, Z.G., 2012. Sensing crop nitrogen status with fluorescence indicators. A review. Agronomy for sustainable development 32, 451-464.

Trojak, M., Skowron, E., 2017. Role of anthocyanins in high-light stress response. World Scientific News 81, 150-168. 
Villar-Salvador, P., Uscola, M., Jacobs, D.F., 2015. The role of stored carbohydrates and nitrogen in the growth and stress tolerance of planted forest trees. New Forests 46, 813-839. Wellburn, A.R., 1994. The spectral determination of chlorophylls a and b, as well as total carotenoids, using various solvents with spectrophotometers of different resolution. J Plant Physiol 144, 307-313.

Wickham, H., 2016. ggplot2: Elegant Graphics for Data Analysis. Springer.

Wijewardane, N.K., Ge, Y., Morgan, C.L., 2016. Moisture insensitive prediction of soil properties from VNIR reflectance spectra based on external parameter orthogonalization. Geoderma 267, 92-101.

Wold, S., Sjöström, M., Eriksson, L., 2001. PLS-regression: a basic tool of chemometrics. Chemometrics Intellig. Lab. Syst. 58, 109-130.

Wood, C., Reeves, D., Himelrick, D., 1993. Relationships between chlorophyll meter readings and leaf chlorophyll concentration, $\mathrm{N}$ status, and crop yield: a review. In, Proceedings of the Agronomy Society of New Zealand, pp. 1-9.

Workman Jr, J., Weyer, L., 2012. Practical guide and spectral atlas for interpretive nearinfrared spectroscopy. CRC press.

Yang, S., Han, Y., Chang, Y., Park, J., Park, Y., Chung, H., Yeo, H., 2018. Classification of the hot air heat treatment degree of larch wood using a multivariate analysis of near-infrared spectroscopy. J Wood Sci. 64, 220-225.

Yihu, S., Jinfeng, C., Xueling, Y., 2009. Inheritance of anthocyanin contents in leaves of chili pepper. J. Nanjing Agricult. Univ.

Zhang, Y., Liu, P., Kong, Q., Xing, S., Liu, X., Sun, L., 2017. The Contents of Terpene Trilactone and Flavonoid in Leaves of Seedlings from Ancient Female Ginkgo Trees in China. Horticultural Plant Journal 3, 165-171. 
Zhao, P., Cao, J., 2016. Wood species identification using spectral reflectance feature and optimal illumination radian design. Journal of forestry research 27, 219-224. 


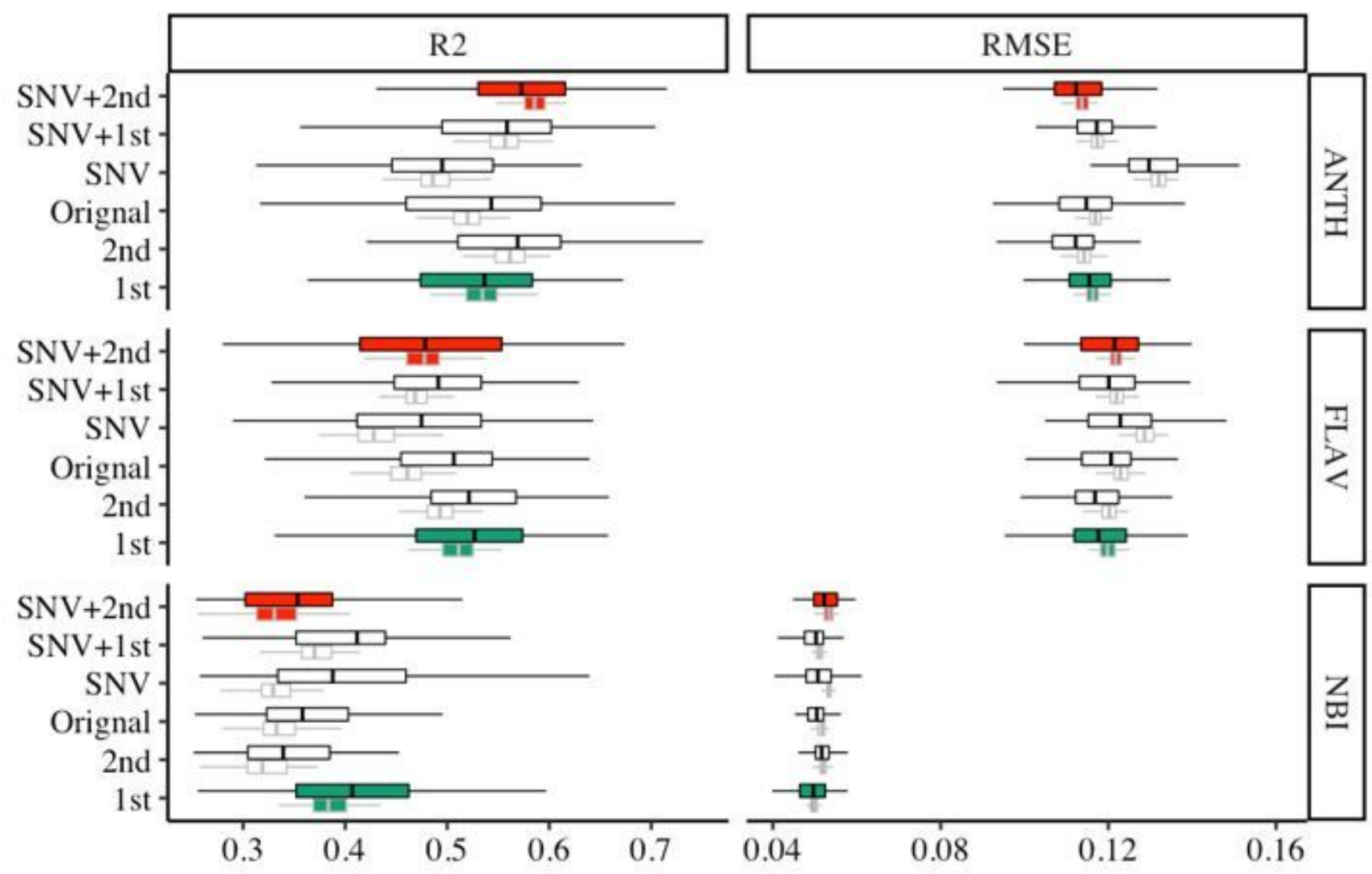

Cal 官 Val

Figure 1

Distribution (95\% confidence intervals) of calibration and validation statistics from 200 simulations of models predicting ANTH, FLAV and NBI with full length NIR spectra. Each model permutation included $80 \%$ of the data for internal calibration and the remaining $20 \%$ for validation. R2: coefficient of determination of cross-validation; RMSE: root-mean-square error of cross-validation; The black vertical line in each box represents median value, the red colour box represents the SNV+2nd model. the green colour box represents the 1 st model. 

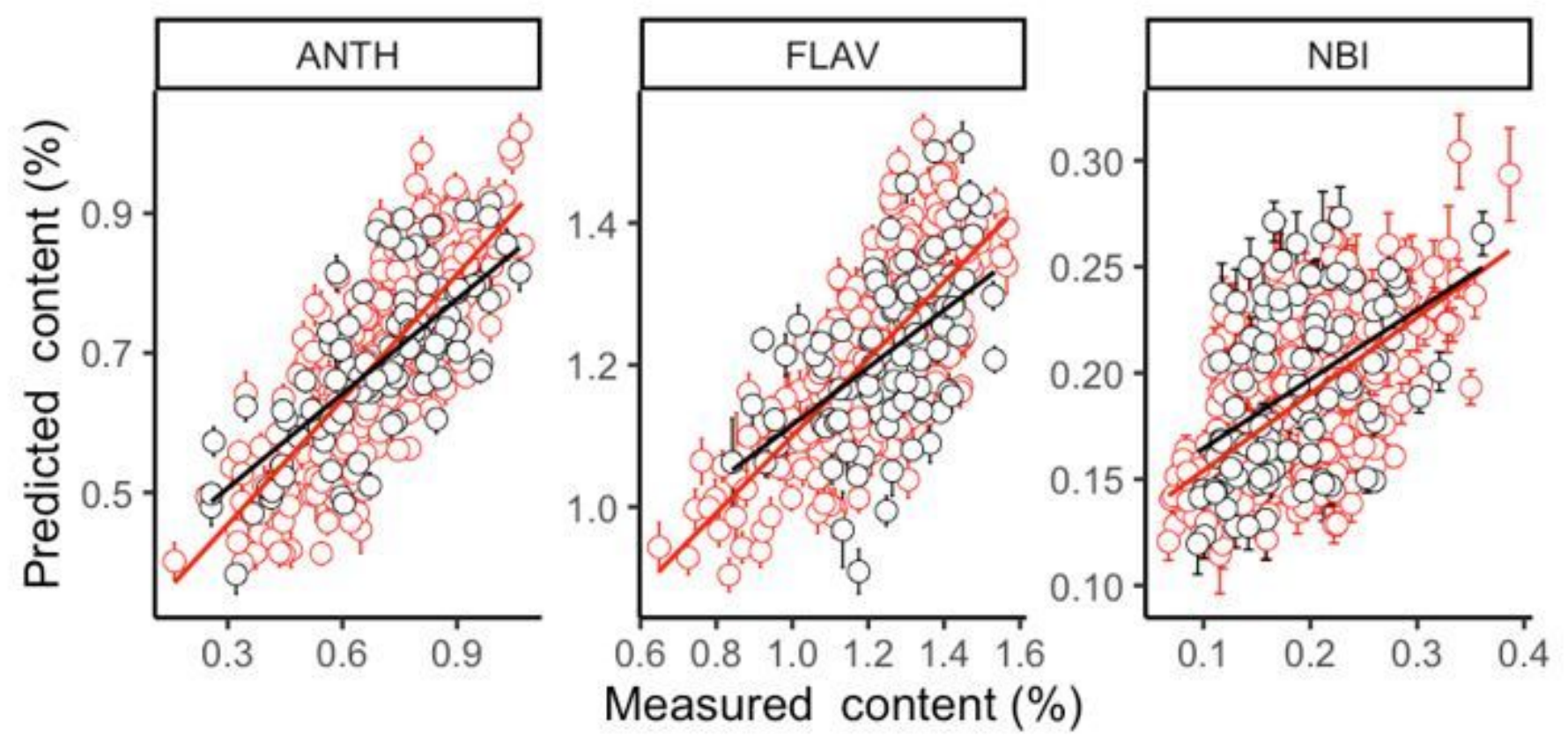

$\ominus \mathrm{Cal} \ominus \mathrm{Val}$

Figure 2

Measured and predicted ANTH, FLAV and NBI contents with full length of NIR spectra. Error bars for predicted values represent the standard deviations obtained from the 200 simulated models.

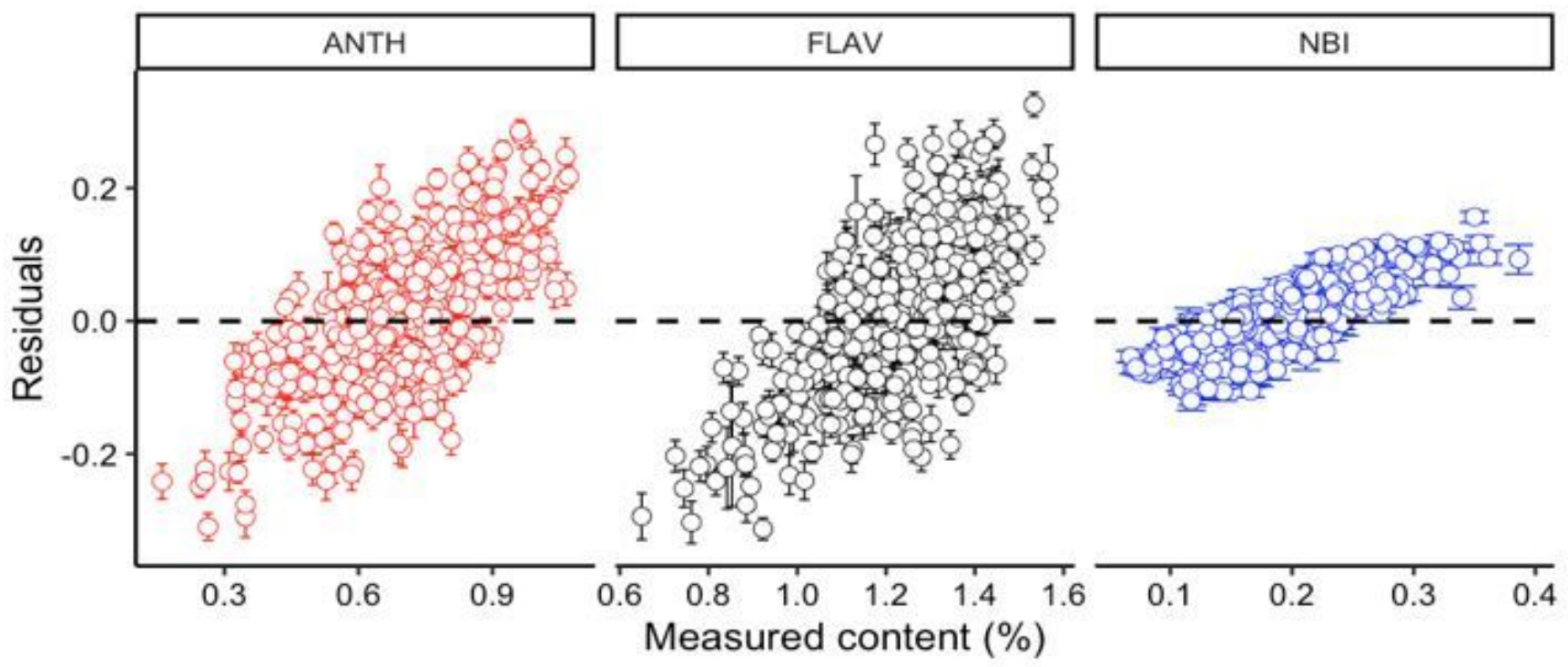

Figure 3

Residuals plotted against measured ANTH, FLAV and NBI with full length of spectra. Error bars for predicted values represent the standard deviations obtained from the 200 simulated models. 


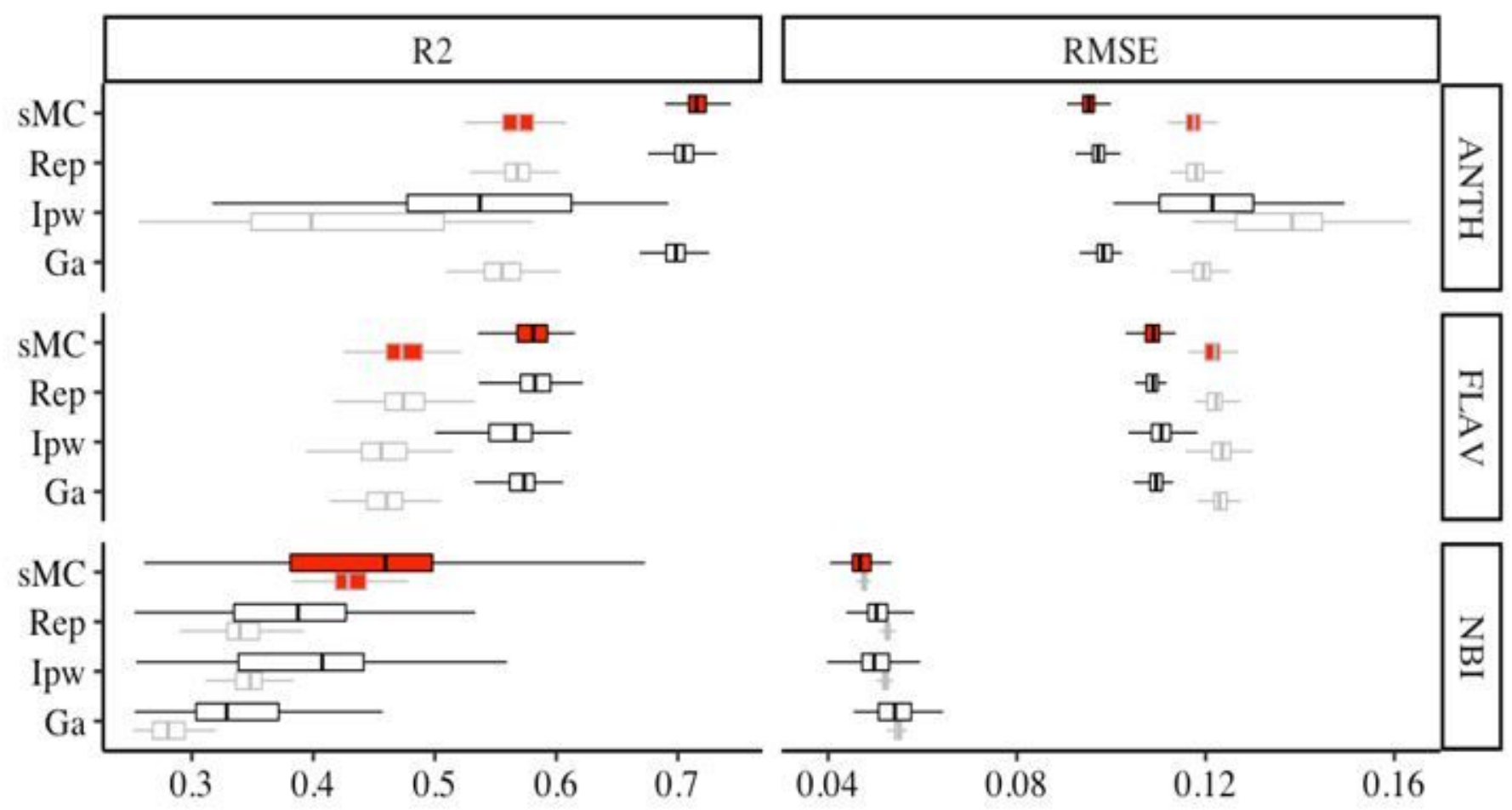

$\mathrm{Cal}$ 帛 $\mathrm{Val}$

Figure 4

Distribution (95\% confidence intervals) of calibration and validation statistics from 200 simulations for models predicting ANTH, FLAV and NBI contents using SMC, Rep, Ipw and Ga variable selection. Each model permutation included $80 \%$ of the data for calibration and the remaining $20 \%$ for validation. R2: coefficient of determination of cross-validation; RMSE: root-mean-square error of cross-validation; The black vertical line in each box represents median value, the red colour box represents the SMC model. 


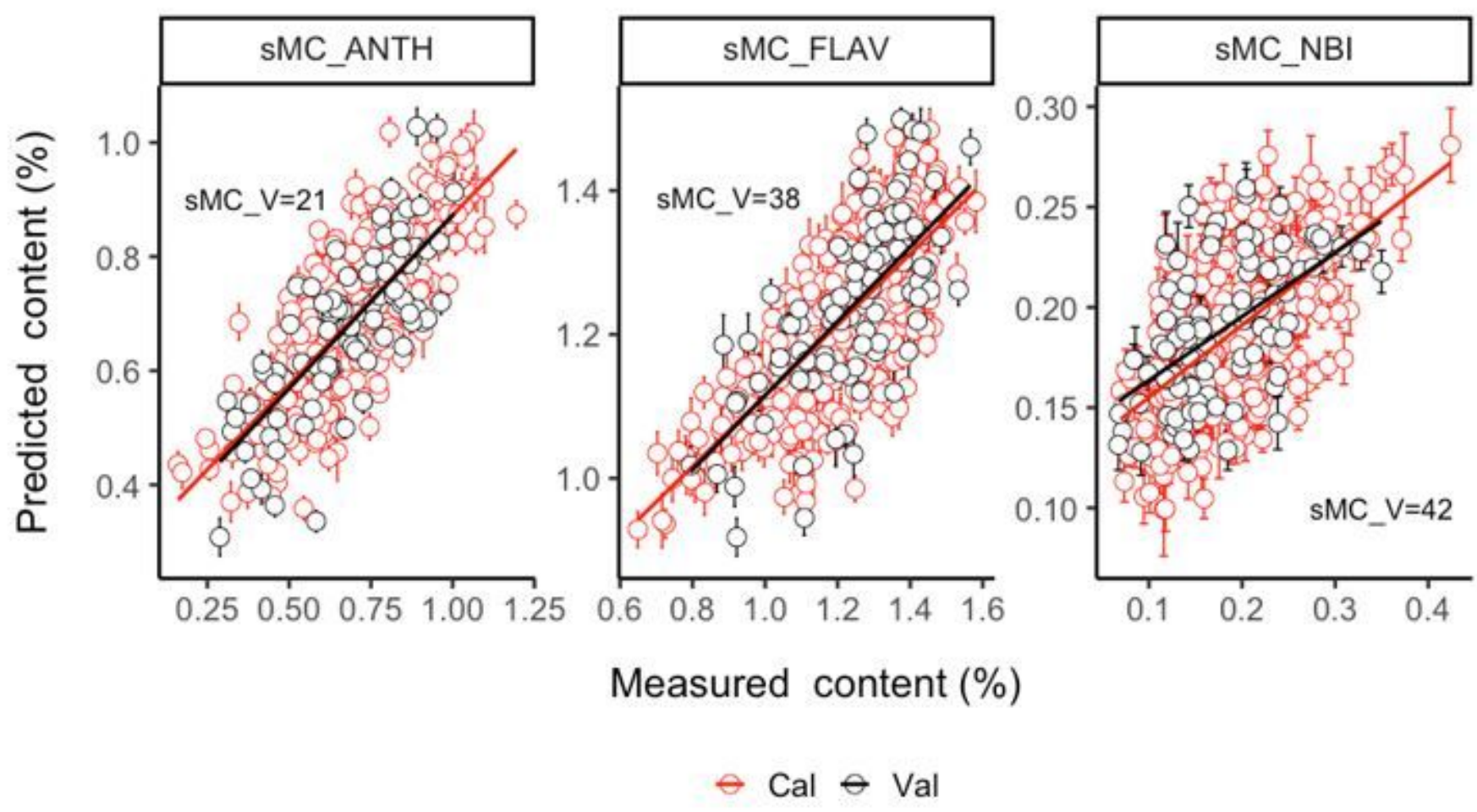

Figure 5

Measured and predicted ANTH, FLAV and NBI contents with SMC selected NIR spectra. Error bars for predicted values represent the standard deviations obtained from the 200 simulated models. sMC_V: the total selected number of variables.

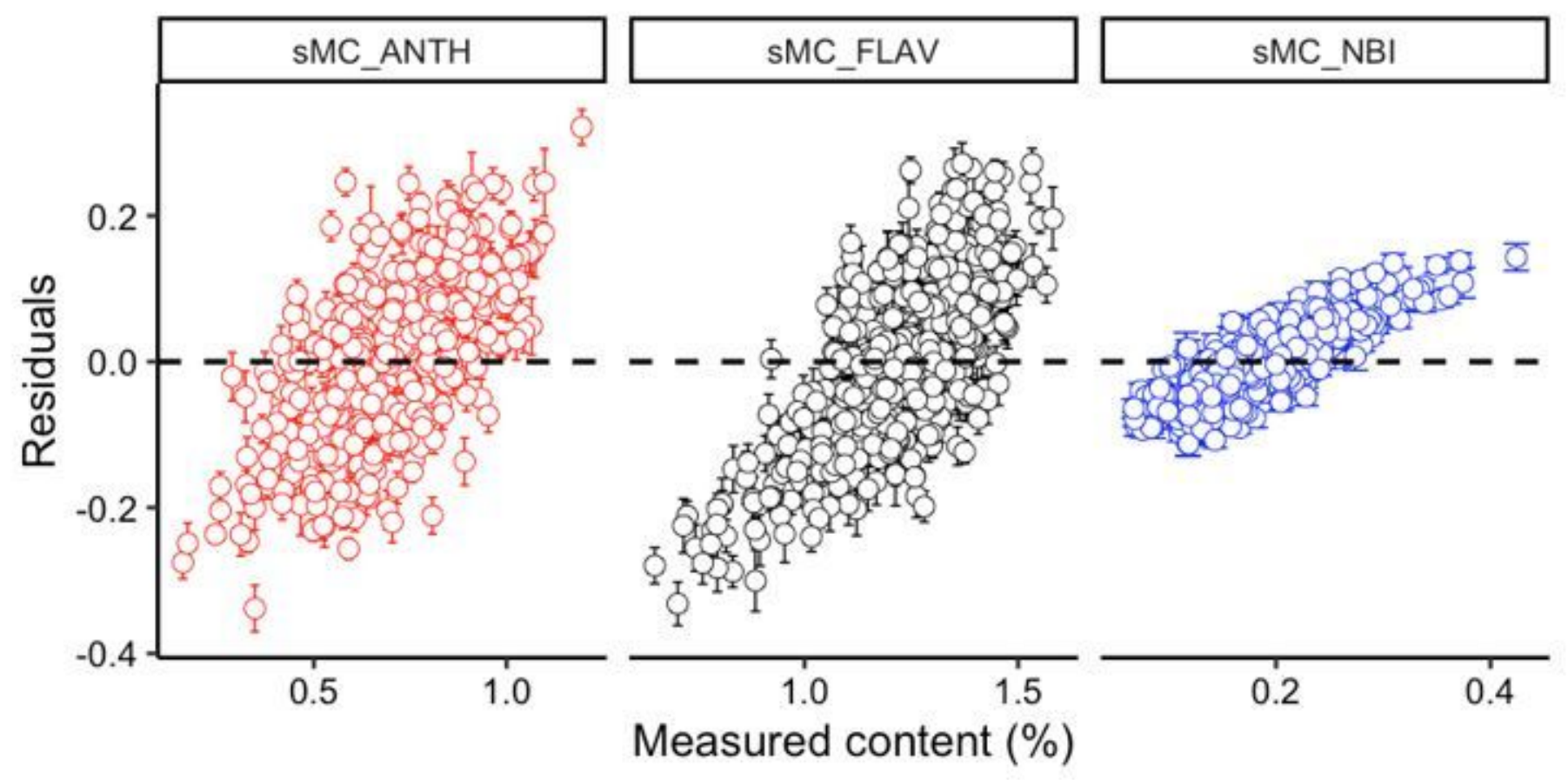

Figure 6 
Residuals plotted against measured ANTH, FLAV and NBI with sMC selected spectra. Error bars for predicted values represent the standard deviations obtained from the 200 simulated models.

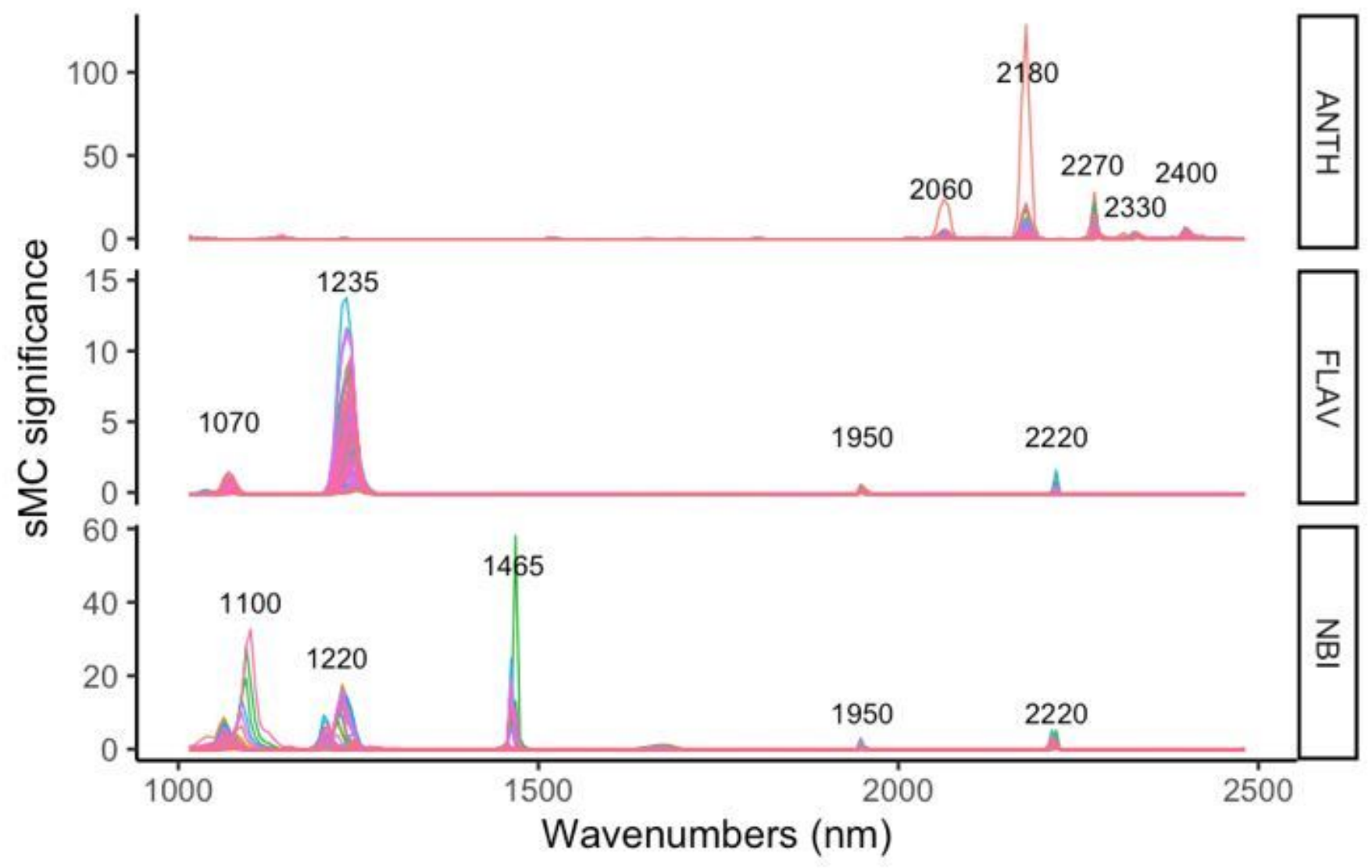

Figure 7

Spectra influence in ANTH, FLAV and NBI models that randomly being conducted 200 times; each line means one time of modelling with $\mathrm{SMC}$ variable selection. 


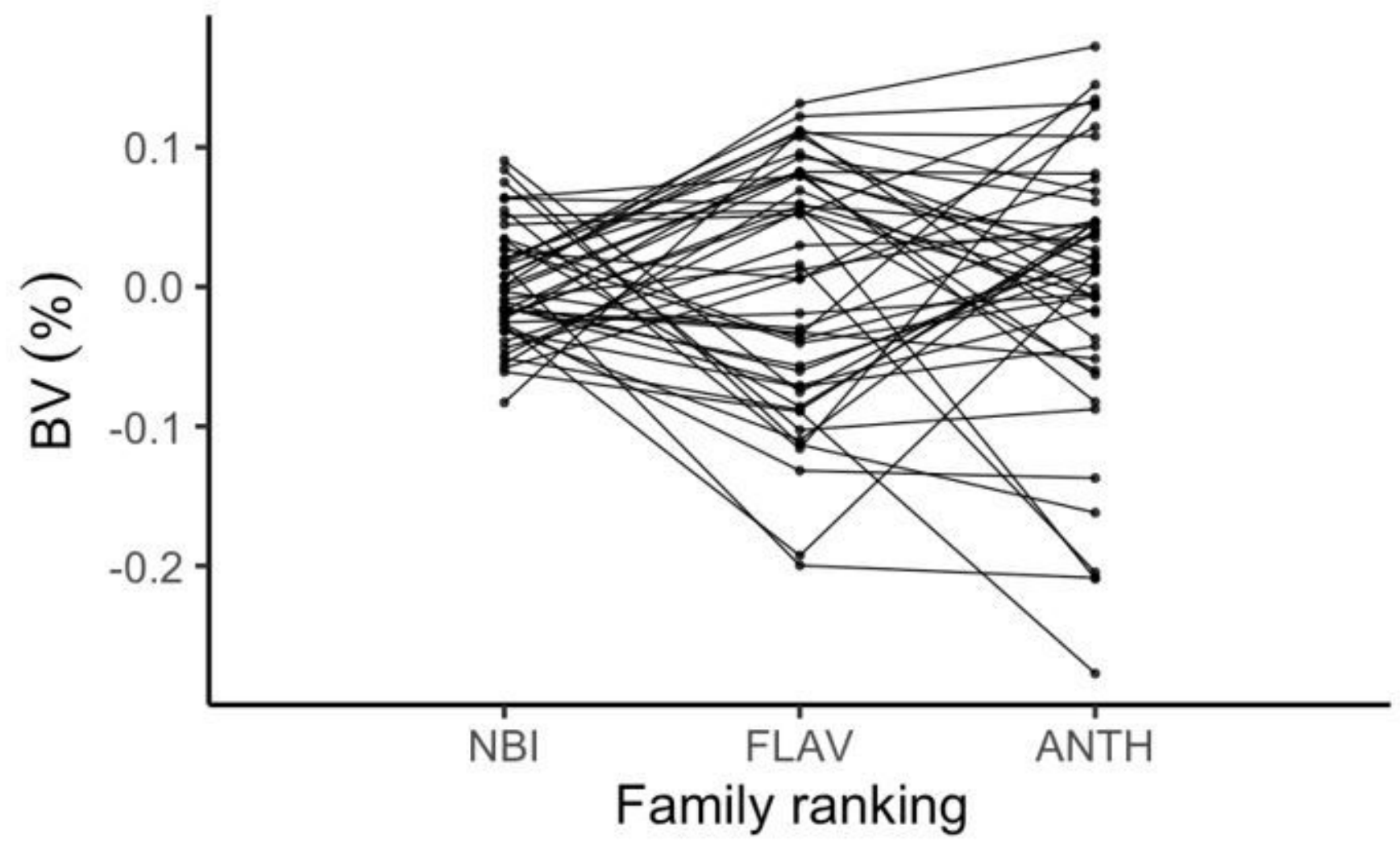

Figure 8

Family ranking for ANTH, FLAV and NBI content in Sassafras tzumu at age 2. Family values are expressed as deviation from each trait mean. BV: Breeding values. 


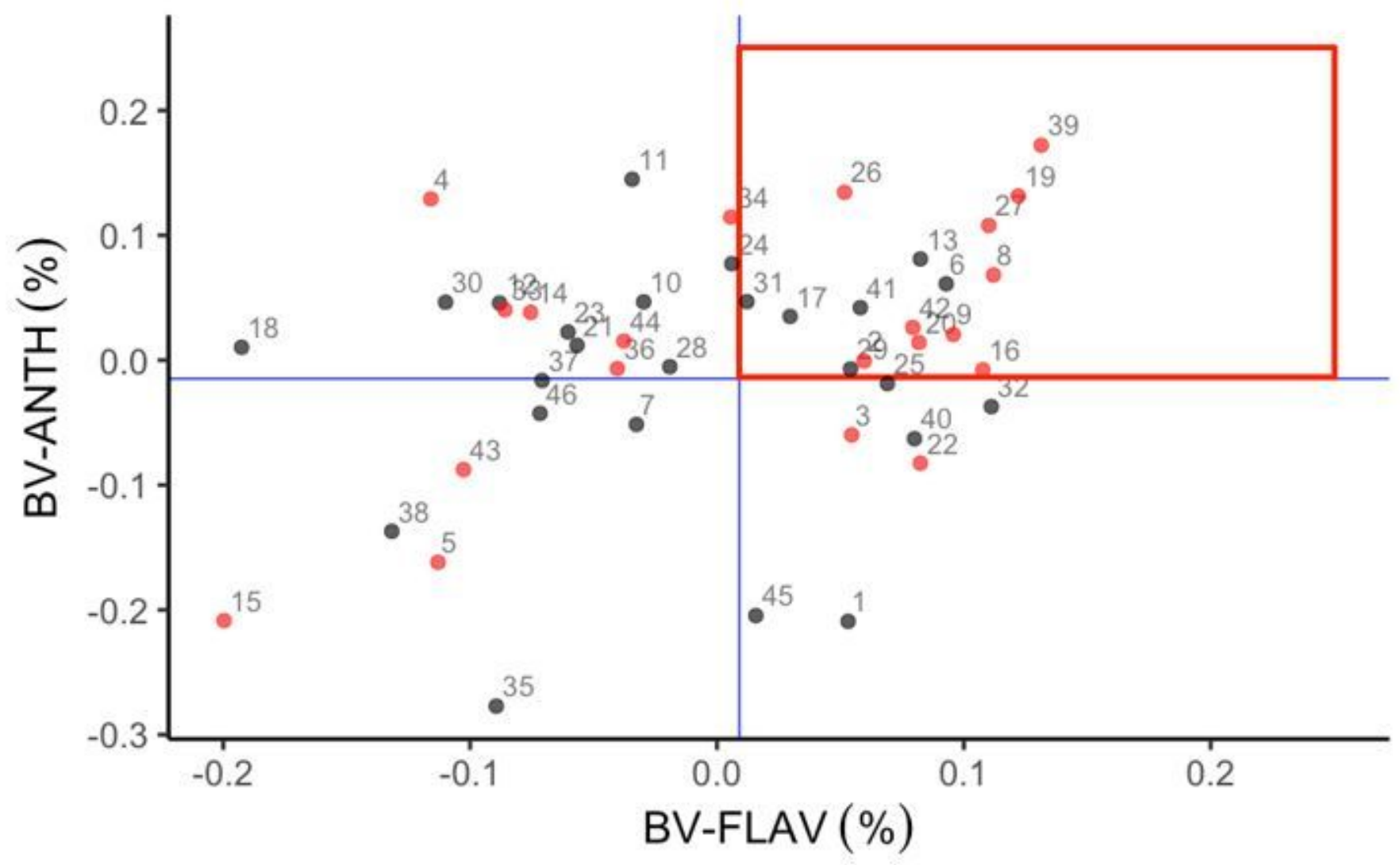

Figure 9

Relationship between ANTH, FLAV and NBI content breeding values of Sassafras tzumu families at age 2. BV-ANTH: breeding value of ANTH; BV-FLAV: breeding value of FLAV; the blue solid line: the mean value of each trait breeding value; red square: the region that most interesting. 